\title{
Rietveld crystal structure refinement of a natural rhombohedral grossular-andradite garnet from Serbia
}

\author{
Pavle TANČIĆ ${ }^{1, *}$ and Aleksandar KREMENOVIĆ ${ }^{2}$ \\ 1 Geological Survey of Serbia, Rovinjska 12, 11000 Belgrade, Serbia \\ 2 University of Belgrade, Laboratory of Crystallography, Faculty of Mining and Geology, Đušina 7, 11000 Belgrade, Serbia
}

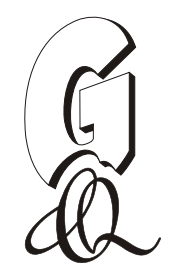

Tančić, P., Kremenović, A., 2022. Rietveld crystal structure refinement of a natural rhombohedral grossular-andradite garnet from Serbia. Geological Quarterly, 66: 7, doi: 10.7306/gq.1639

Associate Editor: Tomasz Bajda

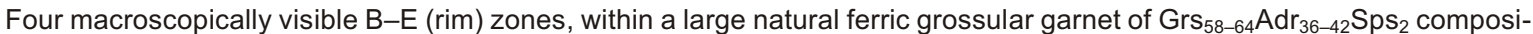
tion, are described by means of Rietveld refinements of the crystal structures in a series of six space groups, followed by comparative analysis of the $R$-values, site occupancy factors, and bond lengths and angles. The garnet crystallized in the rhombohedral $R^{-} 3 c$ space group. Various polyhedral distortions and structural order-disorder variations between the zones studied are also described and discussed. The rhombohedral symmetry of the ferric grossular garnet analysed can be regarded as primary, residual strain being a secondary cause for its slight optical anisotropy.

Key words: ferric grossular garnet, XRPD, Rietveld method, crystal structure, $R^{-} 3 c$ space group, order-disorder.

\section{INTRODUCTION}

Garnets are among the most widely occurring minerals on Earth. They are an important group of rock-forming minerals that are stable over a wide range of temperatures (up to $2000^{\circ} \mathrm{C}$ ), pressures (up to $\sim 25 \mathrm{GPa}$ ), and chemical composition. According to the International Mineralogical Association (IMA) nomenclature, the garnet supergroup includes all minerals isostructural with garnet regardless of what elements occupy the four atomic sites, i.e., the supergroup includes several chemical classes. The general formula for the garnet supergroup minerals is $\left\{X_{3}\right\}\left[Y_{2}\right]\left(Z_{3}\right) \varphi_{12}$, where $X, Y$ and $Z$ refer to dodecahedral, octahedral, and tetrahedral sites, respectively, and $\varphi$ is $\mathrm{O}, \mathrm{OH}$, or $\mathrm{F}$. Most garnets are cubic, of space group la-3d (no. 230), but two $\mathrm{OH}$-bearing species (henritermierite and holtstamite) have tetragonal symmetry, space group, $14_{1} /$ acd (no. 142), and their $X, Z$, and $\varphi$ sites are split into more symmetrically unique atomic positions. The total charge at the $Z$ site and symmetry are criteria for distinguishing groups, whereas the dominant-constituent and dominant-valency rules are critical in identifying species. Twenty-nine species belong to one of five groups: the tetragonal henritermierite group and the isometric bitikleite, schorlomite, garnet, and

\footnotetext{
* Corresponding author, e-mail: pavletan@gmail.com
}

Received: July 5, 2021; accepted: January 22, 2022; first published online: February 21, 2022 berzeliite groups with a total charge at $Z$ of 8 (silicate), 9 (oxide), 10 (silicate), 12 (silicate), and 15 (vanadate, arsenate), respectively (Grew et al., 2013).

Species of the grossular-andradite $\left\{\mathrm{Ca}_{3}\right\}\left[\mathrm{Al}, \mathrm{Fe}^{3+}\right]_{2}\left(\mathrm{Si}_{3}\right) \mathrm{O}_{12}$ solid-solution binary series, occurring in a variety of geological environments, are known to appear in the form of zoned crystals (Deer et al., 2013; Tančić et al., 2012a and references therein). A substantial number of previously-observed grossular-andradite garnets exhibit optical anisotropy and non-cubic low symmetry in various space groups, such as: $\Gamma 1$ (Takéuchi et al., 1982; Allen and Buseck, 1988; Kingma and Downs, 1989; Frank-Kamenetskaya et al., 2007; Kobayashi et al., 2013; and Nakamura et al., 2016); Fddd (Takéuchi et al., 1982; Gali, 1984; Frank-Kamenetskaya et al., 2007; Badar et al., 2016); Fddd or C2/c (Hirai and Nakazawa, 1986) and $R$ 3c or Fddd (Tančić et al., 2020).

To the best of our knowledge, only three optically anisotropic and oscillatory zoned grossular-andradite garnet samples from Serbia have been characterized in more or less detail by Tančić et al. (2012a, 2020), Srećković-Batoćanin et al. (2014) and Kostić et al. (2021), i.e. from skarns of Kopaonik Mt., Rogozna Mt. and Rudnik Mt., respectively.

The macroscopically-zoned garnet from Meka Presedla (Kopaonik Mt., Serbia) studied in this paper was previously characterized by Tančić et al. (2012a). It is slightly anisotropic throughout, without the presence of isotropic areas. Based on electron microprobe analysis (EMPA) median chemical compositions, considerable inversely related variation is observed only by the $\mathrm{Al}^{3+}-\mathrm{Fe}^{3+}$ substitutions in the octahedral site, and a $\mathrm{Grs}_{58-64} \mathrm{Adr}_{36-41} \mathrm{Sps}_{2}$ composition was determined [mineral 
name symbols such as Adr, Grs and Sps refer to andradite, grossular, and spessartine, respectively (Warr, 2021). Such composition therefore defines this garnet more specifically as ferric grossular]. FT-IR and Raman bands are consistent with the chemical composition. All of the zones should be considered as anhydrous, formed under conditions of miscibility and without gaps. They represent solid solutions, rather than mixtures. Formation temperatures from $\sim 600$ to $720^{\circ} \mathrm{C}$, and pressures of $\sim 2-3$ kbars, are derived. Among five possible causes for the slightly optical anisotropy, three were rejected, because: (1) the crystal is microscopically untwinned; (2) no rare earth elements (REE) were detected; and (3) there was no distribution of $\mathrm{OH}^{-}$groups due to hydro-garnet substitution.

The ferric grossular core (zone A) with $\mathrm{Grs}_{64 \pm 1} A \mathrm{dr}_{36 \pm 1} \mathrm{Sps}_{2}$ composition (Tančić et al., 2012a) was further crystallographically studied by Tančić et al. (2020). The procedure applied included detailed analysis of the powder diffraction patterns, and Rietveld refinements of the crystal structures in a series of 18 space groups and two mixtures, followed by the comparative analysis of the $R$-values, site occupancy factors (hereinafter sof's), and bond lengths and angles. It was shown to be not cubic, neither as mono phase, nor as multiple phases in a mixture. Structural dissymmetrization occurred, and it crystallized in disordered rhombohedral $R 3 c$ or orthorhombic Fddd space groups, the first one being more probable. Besides establishing lower symmetry (5), which could be treated as primary cause, residual strain (4) was also not excluded as a possible secondary cause for its slight optical anisotropy.

In the present study, the four remaining, B-E, zones of the $\mathrm{GrS}_{58-64} \mathrm{Adr}_{36-41} \mathrm{Sps}_{2}$ ferric grossular (Tančić et al., 2012a) with $\mathrm{GrS}_{62 \pm 1} \mathrm{Adr}_{38 \pm 1} \mathrm{Sps}_{2}$ (B), Grs ${ }_{59 \pm 2} \mathrm{Adr}_{41 \pm 2} \mathrm{Sps}_{2}$ (C), Grs ${ }_{58 \pm 2} \mathrm{Adr}_{42 \pm 2}$ $\mathrm{Sps}_{2}$ (D) and $\mathrm{Grs}_{58 \pm 1} \mathrm{Adr}_{42 \pm 1} \mathrm{Sps}_{2}$ (E, rim) compositions, were analysed. Our primary goal was to perform an X-ray powder diffraction (XRPD) study of the crystal structure by the Rietveld method in the $R 3 c$ and Fddd space groups, i.e. to check what could be the true space group of its crystallization between these two. These results were compared with those for the la $3 d, R 3, C 2 / c$ and $\Gamma 1$ space groups. All of the results obtained were also further compared with those for zone $A$
(Tančić et al., 2020). For the space group definition it was mainly the chosen distances, sof's and lower comparative $R$-values which were mostly, as argued in our previous studies, the decisive factors not only in vast majority of the low-symmetry grossular-andradite garnets (Tančić et al., 2020), but also in other characteristic natural mineral solid solutions with $\mathrm{Al}^{3+}-\mathrm{Fe}^{3+}$ substitutions over the octahedral sites (Tančić et al., 2012b). The XRPD method was used in order to avoid any kind of "Umweganregung" and/or "Aufhellung" (Rossmanith and Armbruster, 1995).

\section{MATERIALS AND METHODS}

As described by Tančić et al. (2012a), the macroscopically-zoned ferric grossular garnet investigated from the Meka Presedla locality (Kopaonik Mt., Serbia) was initially a spherical mega-crystal with a diameter of $\sim 8 \mathrm{~cm}$. It was cut into parallel slices $\sim 0.5 \mathrm{~cm}$ thick. The largest slice, representing the central part, is shown in Figure 1. In this figure, the macroscopically-visible, different zones marked with solid lines and A-E signs are parallel to the rhombic dodecahedron (110), with a characteristic angle of $120^{\circ}$. Marked zones were carefully cut down, and then powdered and homogenized under alcohol in an agate mortar for several hours, in order to ensure good statistical distribution of the grains.

The samples from the B-E (rim) zones were taken in reflection mode in a bottom-loaded aluminum carrier. Diffraction data were collected on a Phillips PW1710 diffractometer equipped with a graphite monochromator $\left(\mathrm{Cu} \mathrm{K} \alpha_{1}, \lambda=1.540562 \AA\right.$; $\mathrm{Cu}$ $\mathrm{K} \alpha_{2}, \lambda=1.544390 \AA$ ) and a Xe-filled proportional counter, at room temperature $\left(23^{\circ} \mathrm{C}\right)$. Divergence and receiving slits were fixed to $1^{\circ}$ and $0.1 \mathrm{~mm}$, respectively, and the generator was set up at $40 \mathrm{kV}$ and $30 \mathrm{~mA}$. The diffractometer alignment was properly checked using a reference material of powdered crystalline silicon, according to the manufacturer's user manual. Data were collected in scan-step mode, with $0.02^{\circ} 2 \theta$ step, and between $4^{\circ}$ and $135^{\circ} 2 \theta$ and 12.9 step $^{-1}$ for collecting data for Rietveld structure refinements.

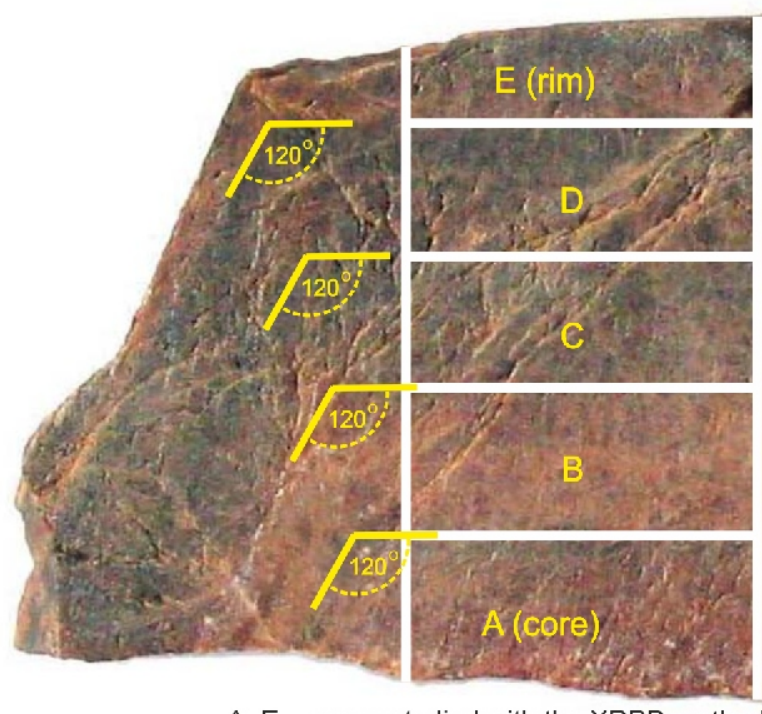

A-E - zones studied with the XRPD method

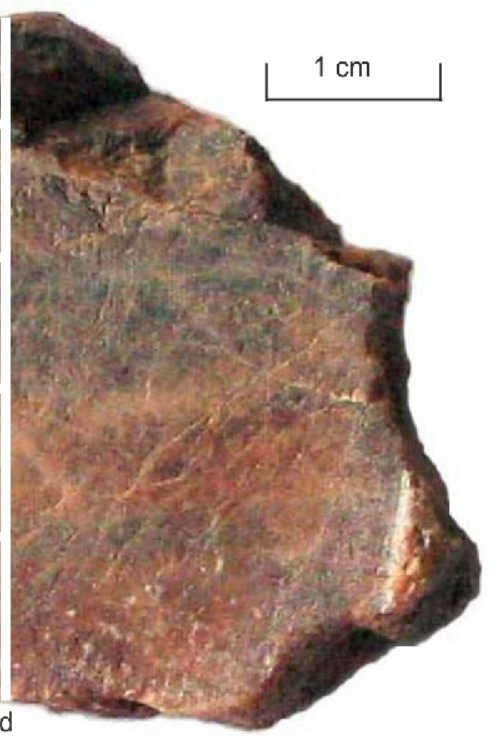

Fig. 1. The macroscopically-zoned large ferric grossular crystal from the Meka Presedla locality studied (Kopaonik Mt., Serbia)

Note that the macroscopically-visible different zones are of the rhombic dodecahedron (110) shape, with a characteristic $120^{\circ}$ angle (modified from Tančić et al., 2012a) 


\section{RESULTS AND DISCUSSION}

\section{XRPD PATTERNS ANALYSIS}

Checking what could be the true space group of the ferric grossular garnet studied started with the comparison and close inspection of the presence and nature of the reflections with Miller's indices 1222 and 888 in the A-E zones. These clearly have diffraction peaks of different intensities and with more or less visible doublets and/or extra-broadening (Fig. 2B, C). On the other hand, other diffraction peaks lack visible doublets, such as the strongest 420 reflection (Fig. 2A), for example. According to the previous observations by Tančić et al. (2020), this seems to be of considerable importance, because it indicates that the garnet studied did not crystallize in the cubic system at all; neither as mono, nor as multiple phases as a mixture, because in this case the observed intensities $\left(Y_{\text {obs }}\right)$ do not match with the calculated Bragg's positions $\left(\mathrm{Y}_{\text {calc }}\right)$ and vice versa. Also, among 18 space groups and two mixtures studied it was more specifically demonstrated that it cannot crystallize in the cubic la $3 d, \Gamma 43 d, 14,32, P 4,32, I a-3$ and 12,3 ; tetragonal $14_{1} /$ acd and $14_{1} / a$; and orthorhombic $\mathrm{Ibca}$ and Pbca space groups; or as cubic la ${ }^{-} 3 d \& l a^{-} 3 d$ and $P 4_{1} 32$ \& la $3 d$ mixtures. The remaining eight possibilities were among the rhombohedral $R-3 c$ and $R$ 3; orthorhombic Fddd; monoclinic $12 / a, 12 / b, 12 / c$ and $C 2 / c$; and triclinic $\Gamma 1$ space groups. Geometrical-mathematical calculations could initially indicate only the following six solutions: $R 3 c, R 3$, Fddd, I2/a, I2/c and C2/c space groups, in very close agreement with previous observations. However, because it was shown by Rietveld crystal structure refinements that there were no significant differences between Al sof's and their corresponding $\mathrm{Y}-\mathrm{O}$ distances over the octahedral $\mathrm{Y}$ sites, the $R 3,12 / a, 12 / b, 12 / c, C 2 / c$ and $\digamma 1$ space groups were also excluded as possibilities, leaving only the $R 3 c$ and Fddd space groups (Tančić et al., 2020).

\section{CRYSTAL STRUCTURE REFINEMENTS}

Two types of crystal structure were determined using the Rietveld profile method and Fullprof program (Rodriguez-Carvajal, 1990): (1) zones B-D were refined as ferric grossular monophases; and (2) zone E was refined as a mixture of two phases, i.e. ferric grossular and scapolite, because in this zone scapolite is most abundant (Tančić et al., 2012a). Crystal structure refinements of the ferric grossular garnet were performed following the procedure described by Tančić et al (2020), in order to achieve all the necessary conditions for data comparison between the A-E zones. It started from the cubic la $-3 d$ space group, which was nominally assigned for garnet group crystallization (Grew et al., 2013). The pseudo-Voigt peak shape function was assumed. In the last cycle of the refinements, 117 parameters were varied: 100 parameters for the background description, 11 profile parameters (one scale factor, one Eta $(p-v)$ parameter, one overall temperature parameter, three parameters for the description of the halfwidths, one parameter for preferred orientation, two asymmetry parameters, one mixing parameter and one zero point), one parameter for the $a_{0}$ unit cell dimension, and five parameters for the three free oxygen atom coordinates, and two sof's at the dodecahedral and octahedral sites. As is well known, symmetry lowering from the $1 a^{-} 3 d$ space group to the other five space groups studied increases the number of ions in special and general positions, and the parameters of their atom coordinates, unit cell dimensions and sof's. For zone $\mathrm{E}$, an additional $23 \mathrm{pa}$ rameters were varied for scapolite in the $14 / \mathrm{m}$ space group
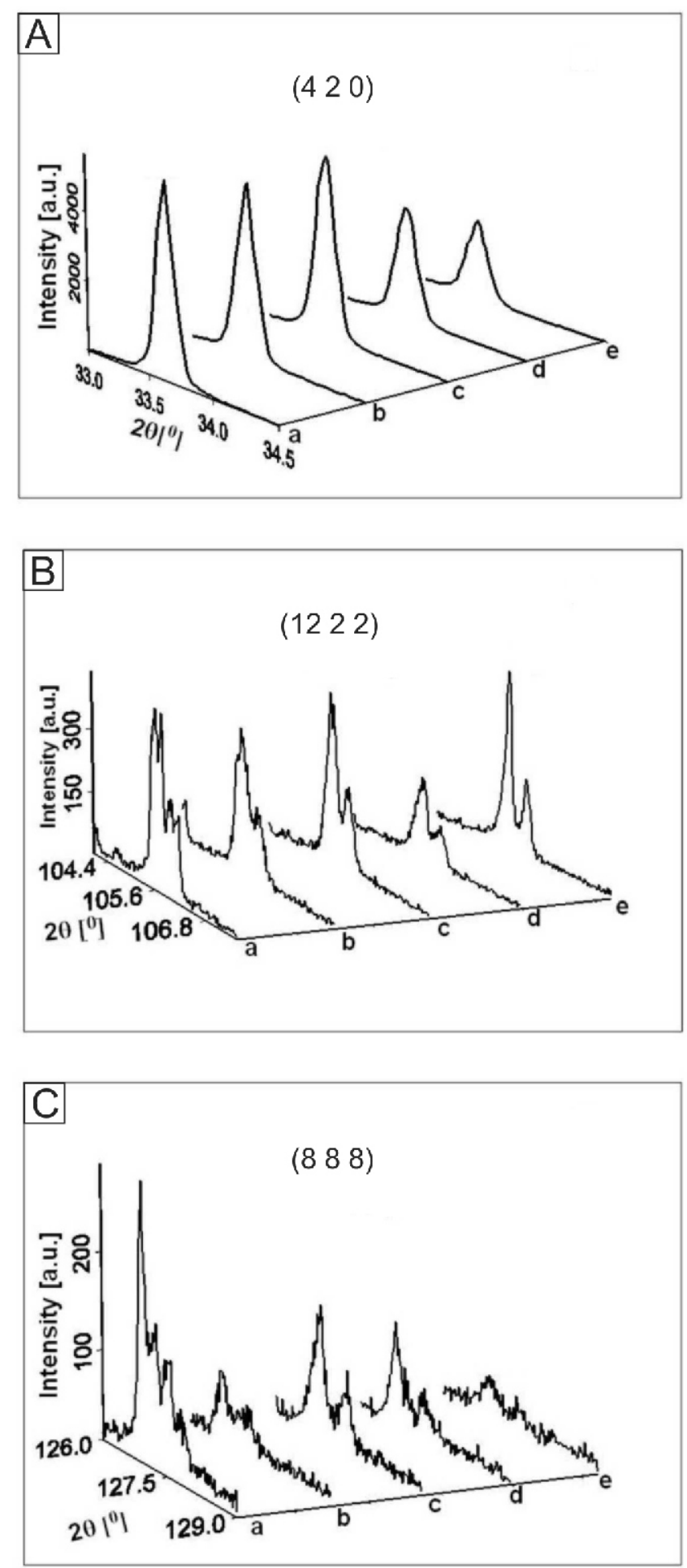

Fig. 2. Comparative powder diffraction patterns of the $A-E$ zones for the three different angle regions and with reflections marked with $h k l ' s$ belonging to the $l^{-} 3 d$ space group: A - 420; B - 122 2; C - 888

Marks: a-zone A; b-zone B; c-zone C; d-zone D; e-zone E

(Sherriff et al., 2000): one scale factor, one mixing parameter, two lattice constant parameters, atomic parameters for two free coordinates of the $\mathrm{Ca}^{2+} / \mathrm{Na}^{+}$cations, five free coordinates of the $\mathrm{Si}^{4+} / \mathrm{Al}^{3+}$ cations, ten free coordinates of the oxygen ions, and two sof's for the $\mathrm{Ca}^{2+} / \mathrm{Na}^{+}$and $\mathrm{Cl}^{-} / \mathrm{C}^{2-}$ positions. 
Table 1

Profile and structural parameters, unit cell dimensions, and reliability factors for the $R^{-} 3 c$ space group without constraints

\begin{tabular}{|c|c|c|c|c|c|c|}
\hline \multicolumn{2}{|l|}{ Zone } & $\mathrm{A}(\text { core })^{1}$ & $\mathrm{~B}$ & $\mathrm{C}$ & $\mathrm{D}$ & E (rim) \\
\hline \multicolumn{2}{|l|}{ SCOR } & 2.1962 & 2.3374 & 1.8919 & 1.8017 & 1.6553 \\
\hline \multicolumn{2}{|l|}{ Overall scale f. $\left(\times 10^{-7}\right)$} & $52(3)^{*}$ & $80(4)$ & $66(3)$ & $170(2)$ & $29(2)$ \\
\hline \multicolumn{2}{|l|}{ Eta $(p-v)$ or $m(p-v i i)$} & $0.32(7)$ & $0.29(9)$ & $0.09(6)$ & $0.27(7)$ & $0.12(8)$ \\
\hline \multicolumn{2}{|l|}{ Overall temp. factor } & $0.1(1)$ & $0.3(1)$ & $0.34(8)$ & $0.7(1)$ & $0.40(9)$ \\
\hline \multirow{3}{*}{ Halfwidth parameters } & $U$ & $0.029(6)$ & $0.06(1)$ & $0.000(5)$ & $-0.04(1)$ & $0.013(5)$ \\
\hline & V & $-0.007(8)$ & $-0.04(1)$ & $0.024(7)$ & $0.02(1)$ & $-0.015(8)$ \\
\hline & W & $0.012(2)$ & $0.026(4)$ & $0.015(2)$ & $0.014(4)$ & $0.030(3)$ \\
\hline \multicolumn{2}{|l|}{ Preferred orientation } & $0.72(5)$ & $0.31(6)$ & $0.43(4)$ & $-1.0(1)$ & $0.35(4)$ \\
\hline \multirow{2}{*}{$\begin{array}{l}\text { Asymmetry parame- } \\
\text { ters }\end{array}$} & As 1 & $0.05(5)$ & $0.18(4)$ & $0.05(4)$ & $0.08(5)$ & $0.05(4)$ \\
\hline & As 2 & $0.051(7)$ & $0.067(7)$ & $0.049(6)$ & $0.044(6)$ & $0.039(5)$ \\
\hline \multicolumn{2}{|l|}{$\mathrm{X}$ parameter } & $0.004(1)$ & $0.003(2)$ & $0.007(1)$ & $0.003(1)$ & $0.007(4)$ \\
\hline \multicolumn{2}{|l|}{ Zero-point } & $0.013(6)$ & $0.032(7)$ & $-0.003(6)$ & $0.018(9)$ & $-0.042(6)$ \\
\hline \multicolumn{2}{|l|}{$a_{0}(\AA)$} & $16.852(1)$ & $16.861(1)$ & $16.8824(9)$ & $16.873(2)$ & $16.8615(9)$ \\
\hline \multicolumn{2}{|l|}{$c_{0}(\AA)$} & $10.3252(9)$ & $10.341(1)$ & $10.3308(8)$ & $10.338(1)$ & $10.3386(7)$ \\
\hline \multicolumn{2}{|l|}{$V_{0}\left(\AA^{3}\right)$} & $2539.4(3)$ & $2547.8(5)$ & $2549.9(3)$ & $2548.7(5)$ & $2545.6(2)$ \\
\hline \multicolumn{2}{|l|}{$\mathrm{N}-\mathrm{P}+\mathrm{C}$} & 6417 & 6417 & 6417 & 6417 & 6394 \\
\hline \multicolumn{2}{|l|}{$R_{p}$} & 14.4 & 14.1 & 12.0 & 13.3 & 12.8 \\
\hline \multicolumn{2}{|l|}{$R_{w p}$} & 19.3 & 19.2 & 16.3 & 18.5 & 17.5 \\
\hline \multicolumn{2}{|l|}{$R_{\exp }$} & 11.48 & 11.41 & 11.63 & 14.08 & 14.04 \\
\hline \multicolumn{2}{|l|}{ Conventional $R_{p}$} & 22.0 & 21.9 & 18.8 & 21.5 & 24.2 \\
\hline \multicolumn{2}{|l|}{ Conventional $R_{w p}$} & 25.1 & 25.2 & 21.4 & 25.0 & 26.5 \\
\hline \multicolumn{2}{|l|}{ Conventional $R_{\exp }$} & 14.95 & 14.98 & 15.28 & 19.00 & 21.20 \\
\hline \multicolumn{2}{|l|}{ Chi2 } & 2.83 & 2.83 & 1.97 & 1.73 & 1.56 \\
\hline \multicolumn{2}{|l|}{ Chi2 (Bragg contr.) } & 3.25 & 3.16 & 2.21 & 1.94 & 1.64 \\
\hline \multicolumn{2}{|l|}{ DW-stat. } & 0.9079 & 0.8863 & 1.2388 & 1.3483 & 1.4249 \\
\hline \multicolumn{2}{|l|}{ DW-exp. } & 1.9651 & 1.9651 & 1.9651 & 1.9651 & 1.9724 \\
\hline \multicolumn{2}{|l|}{ GoF } & 1.6 & 1.7 & 1.4 & 1.3 & 1.2 \\
\hline \multicolumn{2}{|l|}{$R_{B}$} & 8.17 & 8.64 & 6.07 & 6.78 & 6.02 \\
\hline \multicolumn{2}{|l|}{$R_{F}$} & 6.80 & 7.42 & 6.31 & 6.94 & 6.24 \\
\hline
\end{tabular}

* - the numbers in parentheses are the estimated standard deviations multiplied with SCOR and refer to the last significant number; ${ }^{1}-$ Tančić et al. (2020)

Crystal structure studies were performed without any constraints in the $l^{-}-3 d, R 3 c, R-F d d d, C 2 / c$ and $\Gamma 1$ space groups (Table 1 and Appendix 1). Namely, as was shown by Tančić et al. (2020), two of these ( $R 3 c$ and $F d d d)$ are of special interest, whereas other four space group refinements were made in this paper mostly for comparison, additional checking and other necessary data collecting. Also, among these space groups, five of them are very significant because of the possibility of the $T_{2 g}$ route, i.e. the phase transition from the ${ }^{-}{ }^{-} 3 d$ to the $R 3 c, F d d d, C 2 / c$ and $\Gamma 1$ space groups (Hatch and Griffen, 1989), which is consistent with the chemical composition of the ferric grossular garnet studied (Tančić et al., 2012a, 2020). For the $R 3 c$ and Fddd space groups, structure studies with applied constraints were also performed (Appendix 2), which were appropriate to the observed chemical compositions of the zones (Tančić et al., 2012a), and calculated from the data given by Novak and Gibbs (1971). All angles were treated without constraints. Standard deviation values were multiplied with SCOR factors (Berar and Lelann, 1991).

Unit cell dimensions, calculated $\mathrm{Ca}$ and $\mathrm{Al}$ sof's, and $R_{\mathrm{B}}$ and $R_{\mathrm{F}}$ reliability factors for the six space groups studied are listed in Appendix 1. At the first sight, it is obvious that the zones studied more or less differ from each other. Namely, unit cell dimen- sions and volumes $\left(V_{0}\right)$, which were in our previous studies were already shown as useful tools for approximate estimation of the $\mathrm{Al}-\mathrm{Fe}^{3+}$ substitutions in the octahedral site (Tančić et al., 2012b; Cvetković and Tančić, 2019), mostly increase from zone A (core) to zones $C$ and/or $D$, and then decrease in zones $D$ and/or $\mathrm{E}$ (rim). For example, in the $\mathrm{la}^{-} 3 d$ space group there were calculated $\mathrm{Al}$ sof's ( $\mathrm{Al}_{\text {calc; }}$; from 59 to 66 at.\%) on the basis of the determined $V_{0}$, and according to the starting data for Grs and Adr by Novak and Gibbs (1971). These are in concordance with their chemical compositions and with the $\mathrm{Al}-\mathrm{Fe}^{3+}$ substitutions in the octahedral site. Namely, the $\mathrm{Al}^{3+}$ cation content decreases from zone $A$ to $D$, with a difference of $\sim 6$ at. $\%$, and it slightly increases in zone E (Tančić et al., 2012a). However, in most of the space groups studied, calculated $\mathrm{Al}$ (and $\mathrm{Ca}$, as well) sof's are more or less inconsistent with the ones expected (Appendix 2), and they are most well expressed in zones $A$ and C. Differences between $A$ and $C$ by comparison with the other zones are also visible from variations in the cubic $a_{0}$ axis (Appendix 1) by the Raman shift of band VII detected (Tančić et al., 2012a), shown in Appendix 3.

In the triclinic $\Gamma 1$ space group, $\beta_{0}$ angles of $90.081(9)^{\circ}$, $90.11(1)^{\circ}$ and $90.12(5)^{\circ}$, in the A, D and E zones, respectively; and $\gamma_{0}$ angles of $89.89(1)^{\circ}$ and $89.922(4)^{\circ}$, in the $B$ and $C$ zones, 


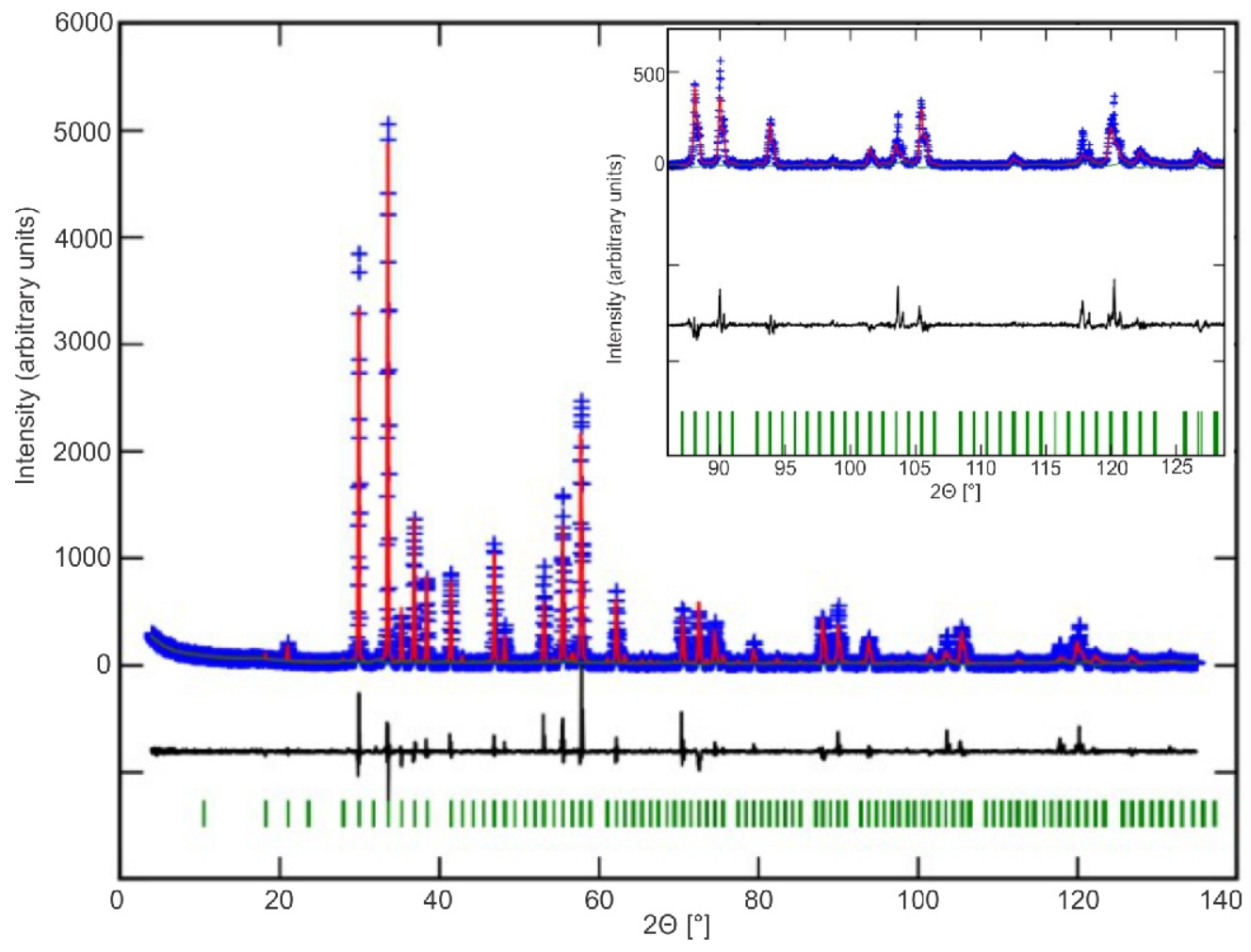

Fig. 3. Final Rietveld plot for the $R^{-} 3 c$ space group of zone $B$

The area of $\sim 86-129^{\circ} 2 \theta$ angle range is magnified for a better view. The computer program plotCIF was used (http://publcif.iucr.org/services/tools/pdcifplot.php). Observed intensities ( $\left.Y_{\text {obs }}\right)$ are shown in blue, calculated intensities $\left(Y_{\text {calc }}\right)$ are shown in red, and differences between observed and calculated intensities $\left(Y_{\text {obs }}-Y_{\text {calc }}\right)$ were presented with black colour, whereas reflection (Bragg) positions were presented with green vertical bars

respectively, also clearly reveal violation of the cubic symmetry (Appendix 1). Therefore, differences between these angles and $90^{\circ}$ are considerable (from $\sim 0.08^{\circ}$ in the $\mathrm{A}$ and $\mathrm{C}$ zones, to $\sim 0.12^{\circ}$ in the $B, D$ and $E$ zones), and increase in the following order: $\mathrm{C}<\mathrm{A}<\mathrm{B}=\mathrm{D}<\mathrm{E}$. Average $<\mathrm{a}_{0}>$ crystallographic unit cell parameters are mostly similar to the $a_{0}$ determined in the $1 a^{-} 3 d$ space group. Also, among three crystallographic unit cell parameters in this space group, two of them are mainly quite similar, whereas the third is significantly different, strongly indicating the rhombohedral crystal system. The same observations may be likewise noticeable in the Fddd and $C 2 / c$ space groups, after adequate transformation of their $c_{0}$ and $a_{0}$ crystallographic axes, respectively.

Furthermore, all of the rhombohedral distortion angles $(\alpha)$ calculated depart significantly by more than $0.004^{\circ}$ from $60^{\circ}$, i.e. from $0.024^{\circ}$ in the $A$ and $D$ zones, to $0.068^{\circ}$ in the $B$ zone in the $R 3 c$ space group; and from $0.026^{\circ}$ in the $A$ and $D$ zones, to $0.054^{\circ}$ in the $\mathrm{B}$ zone in the $R 3$ space group (Appendix 1 ), which shows that the ferric grossular garnet studied is not cubic (Ishizawa and Inagaki, 2008).

Finally, because there are no significant differences between Al sof's over the 4, 4 and 8 octahedral $Y$ sites, which are the required conditions in the $R 3, C 2 / c$ and $\digamma 1$ space groups, respectively (Appendix 1), it was shown that these possibilities were previously justifiably excluded (Tančić et al., 2020). Similarly, it is well known that if the single octahedral $Y$ site in the la- $3 d$ space group is split into two differently occupied sites $Y 1$ and $Y 2$, the symmetry reduces to the orthorhombic Fddd or rhombohedral $R 3 c$ space groups, which are of most significance in our case. However, here it can be seen that there are two identical Al sof's over the octahedral $Y$ sites already in the zone B for the Fddd space group, which could also reasonably indicate that ferric grossular garnet studied cannot crystallize in this space group. Accordingly, the results obtained for this space group will not be provided in detail, but only those which were necessary for required additional analysis and adequate data comparison with the $R 3 \mathrm{c}$ space group.

For the $R 3 c$ space group, the final Rietveld plots are shown in Figures 3-6; while profile and structural parameters, unit cell dimensions, reliability factors, atom parameters, calculated sof's of $\mathrm{Ca}$ and $\mathrm{Al}$, and selected distances and angles, are shown in Table 1 and Appendices 4-7.

By comparison of the Rietveld plots (Figures 3-6), it could be seen that, generally, most of the intensities decrease from zones $A-C$ to zones $D-E$, i.e. from core to rim. Another characteristic is that some peak intensities differ for zones $A$ (Tančić et al., 2020) and $C$ in comparison with zones B, D and E, especially in the area of the $\sim 87-107^{\circ} 2 \theta$ angle range (see also Figure 2). The magnified angle area in Figures $3-6$ is further analyzed to the number of calculated Bragg's positions $\left(\mathrm{Y}_{\text {calc }}\right)$ and differences between starting and ending corresponding $Y_{\text {calc's }}$ $\left(\Delta \mathrm{Y}_{\text {calc }}\right)$, and shown in Appendix 8. Namely, Tančić et al. (2020) demonstrated that in zone $A$ there is the simultaneous existence of diffraction peaks which include more or less clearly visible doublets and/or extra-broadening, whereas some others are without doublets. Although the $R-3 c$ and Fddd space groups have at least two calculated Bragg's positions for each diffraction peak in these selected areas, it is obvious that diffraction peaks without doublets have significantly smaller differences $\left(\Delta \mathrm{Y}_{\text {calc }}\right)$ between starting and ending corresponding $\mathrm{Y}_{\text {calc }}$, 


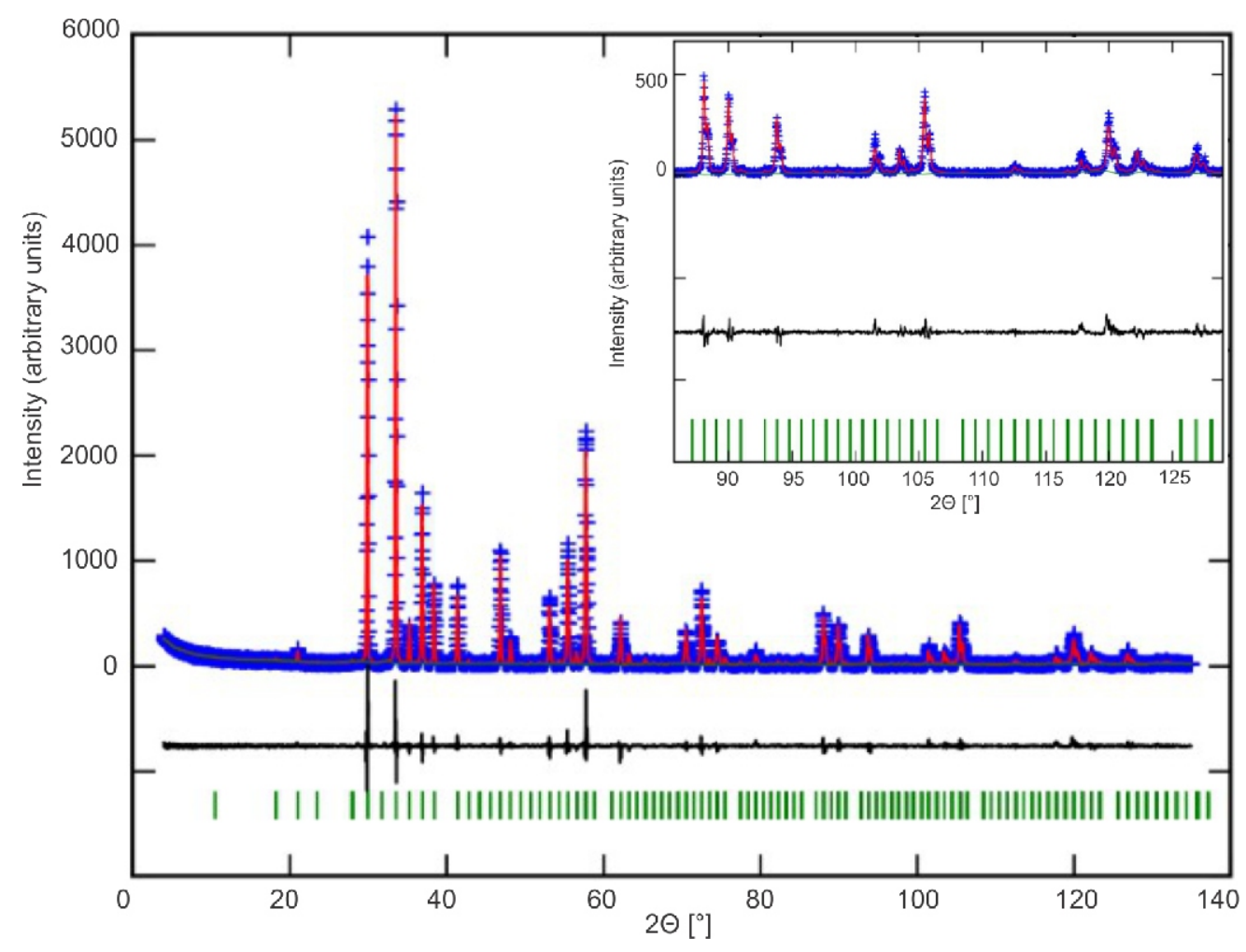

Fig. 4. Final Rietveld plot for the $R^{-} 3 c$ space group of zone $C$

Symbols are the same as in Figure 3

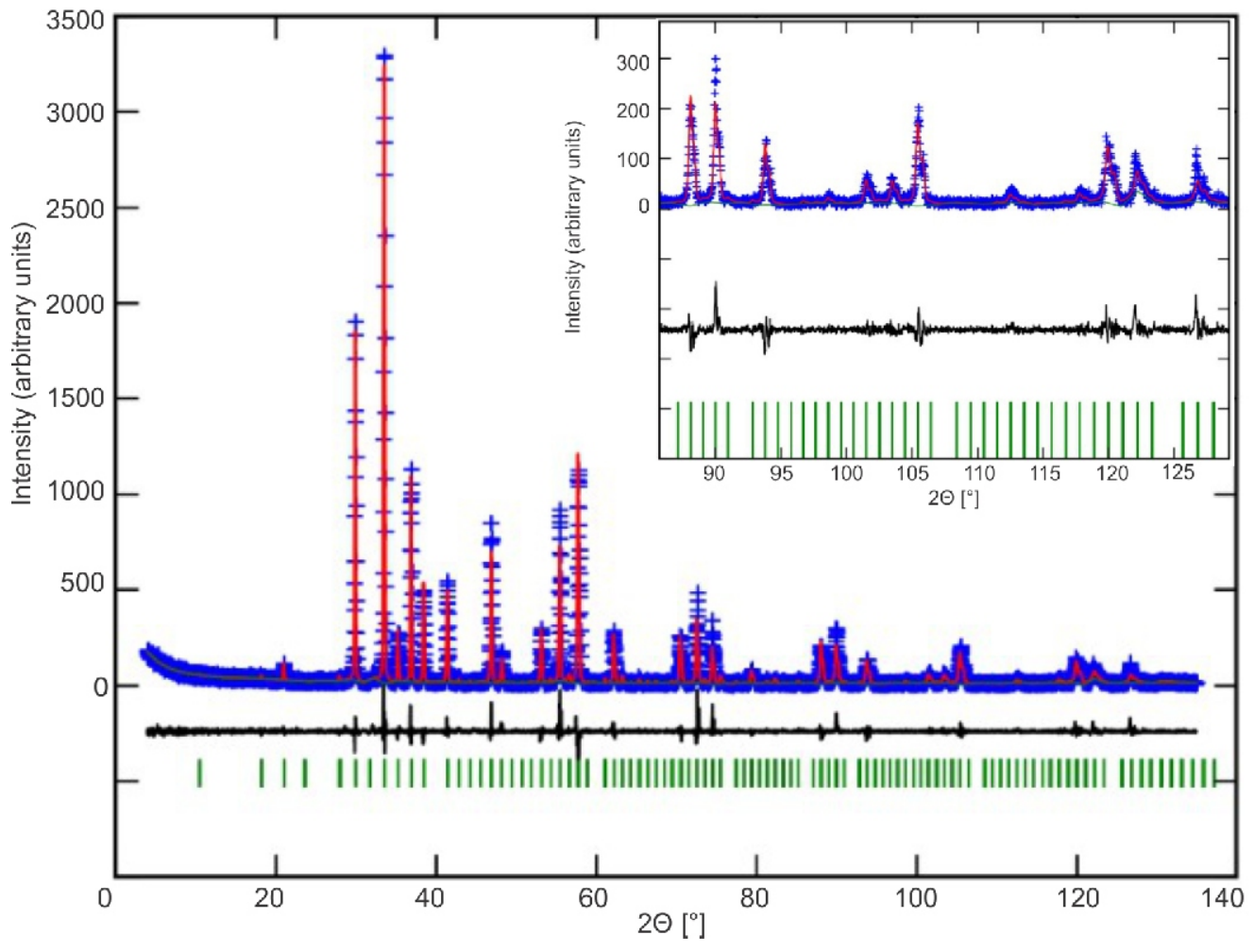

Fig. 5. Final Rietveld plot for the $R^{-} 3 c$ space group of the zone $D$

Symbols are the same as in Figure 3 


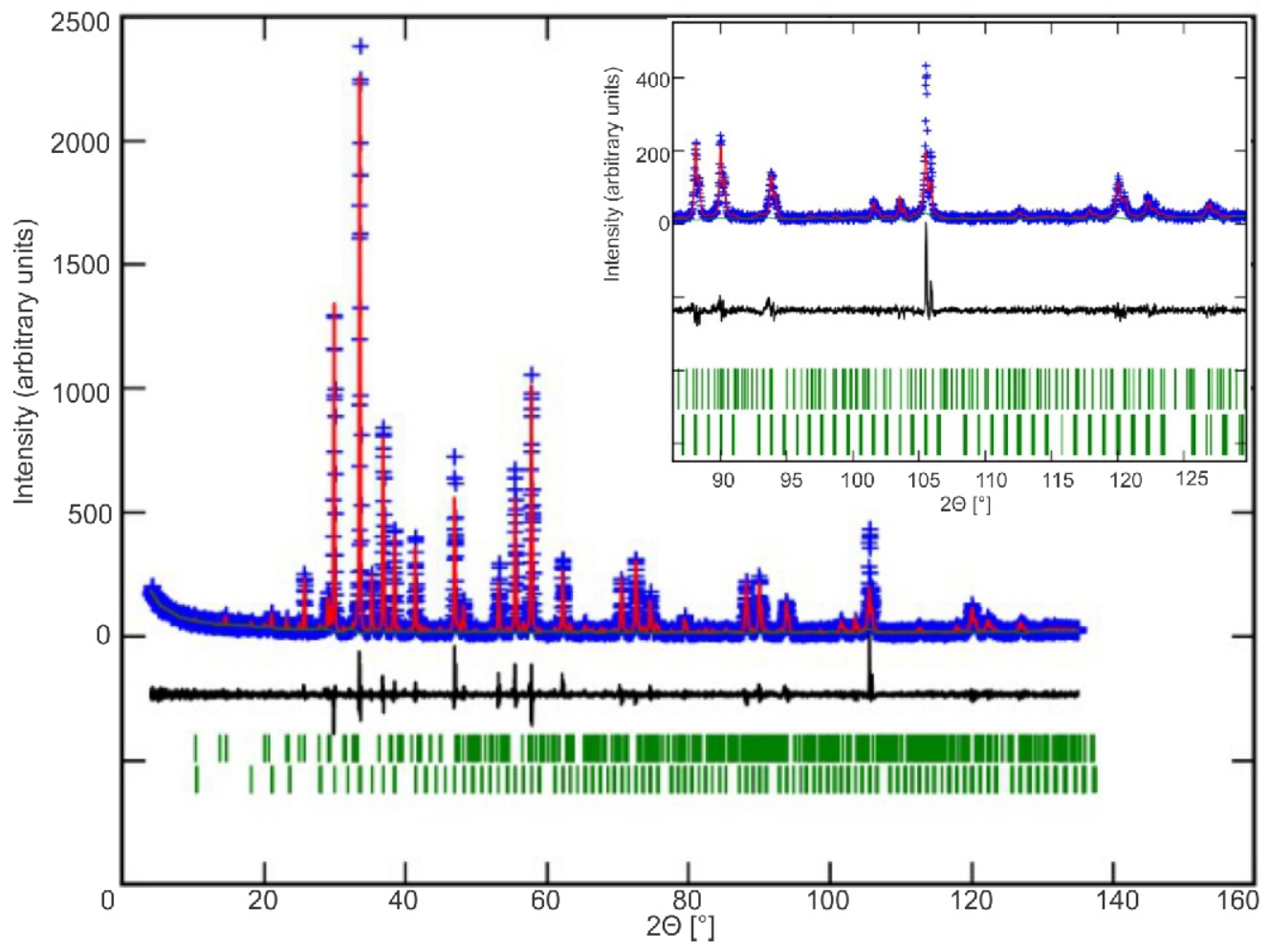

Fig. 6. Final Rietveld plot for the $R^{-} 3 c$ space group of zone $E$

Symbols are the same as in Figure 3. First and second rows with green vertical bars represent minor scapolite and major ferric grossular phases, respectively

i.e. they are mostly within a narrower area than those with doublets in each of the zones studied. The clearest example of such a case is where one single diffraction peak (12 2 0$)$ is in close vicinity to and between two pronouncedly diffraction doublets (884 \& 1222 ).

With refinement of the structure in zone $E$ it was also established that the quantitative contents of ferric grossular is $92(5) \%$ and of scapolite $7.8(7) \%$, consistent with the previous microscopic estimation of $\sim 5-6 \%$ (Tančić et al., 2012a). The scapolite has the following unit cell dimensions: $a_{0}=12.130(2)$ $\AA, c_{0}=7.568(1) \AA$, and $V_{0}=1113.5(3) \AA^{3}$. The ratios of $\mathrm{Ca}: \mathrm{Na}$ $=77(1): 23(1)$ and $\mathrm{Cl}: \mathrm{C}=99(2): 1(2)$ correspond to about $77 \%$ of the meionite composition. Structure refinement with applied constraints shows almost identical results: the quantitative con-
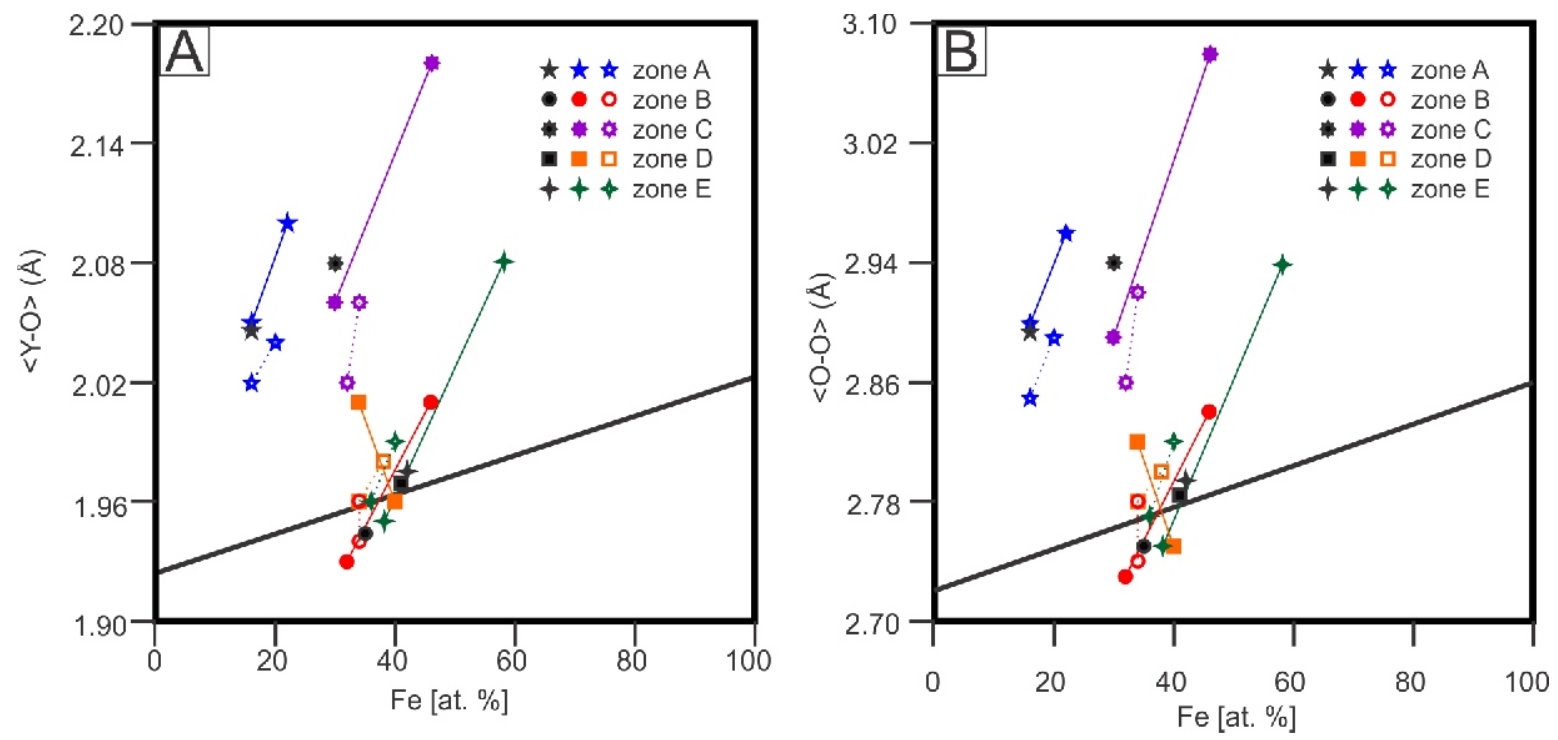

Fig. 7. Variations in $\mathrm{Fe}^{3+}$ and $\mathrm{Al}^{3+}$ over the octahedral sites in $\mathrm{Ia}^{-} 3 d$ (marked with black filled symbols), $R^{-} 3 \mathrm{C}$ (marked with coloured filled symbols and full lines) and Fddd (marked with coloured empty symbols and dotted lines) space groups, by average: a) $\langle Y-O\rangle$; and b) $\langle 0-0\rangle$ distances without constraints 


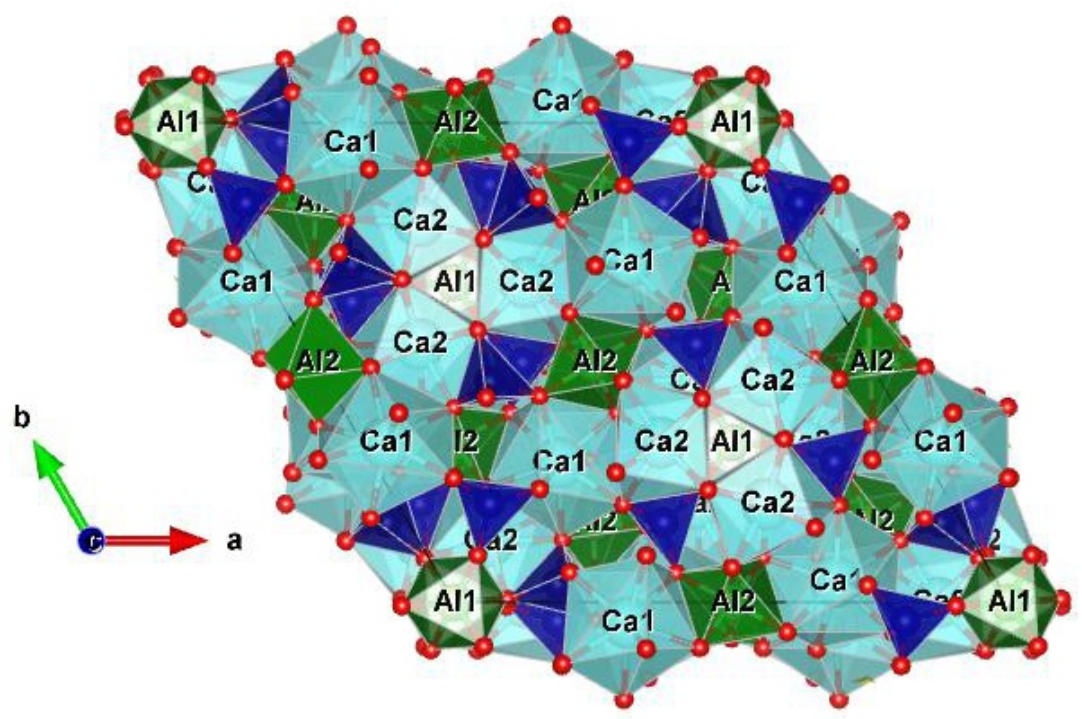

Fig. 8. Polyhedral crystal structure of the ferric grossular garnet studied in the rhombohedral $R^{-} 3 c$ space group viewed down the c-axis

Symbols: Ca1 and $\mathrm{Ca} 2$ dodecahedra - light blue; Al1-Fe1 and Al2-Fe2 octahedra green; $\mathrm{Si}-\mathrm{O}$ tetrahedra - dark blue; oxygen anions - red

tent of ferric grossular is $92(4) \%$ and of scapolite $7.5(6) \%$; unit cell dimensions are $a_{0}=12.130(2) \AA, c_{0}=7.568(1) \AA$, and $V_{0}=$ 1113.7(3) $\AA^{3}$; and ratios are $\mathrm{Ca}: \mathrm{Na}=78(1): 22(1)$ and $\mathrm{Cl}: \mathrm{C}=$ $98(2): 2(2)$. In order to additionally check these compositions, the equation given by Wehrenberg (1971) was used. Namely, taking into account the previously determined characteristic FT-IR band of $609 \mathrm{~cm}^{-1}$ of scapolite (Tančić et al., 2012a), 71 $\%$ of the meionite component was calculated, which correlates relatively well with the structure refinement.

The most important data for comparison between the $R 3 c$ and Fddd space groups is given in Appendix 9. Taking into account all of the studied zones in the Fddd space group without constraints, it can be seen that the differences between Al sof's (hereinafter $\Delta$ Al's) are insignificant, i.e. from 0 to 4 at.\% (average 2.8 at.\%), and with their estimated standard deviations (hereinafter esd's) which exceed these values. On the other hand, $\Delta$ Al's over the octahedral $Y$ sites in the $R$ - $3 c$ space group are much higher, i.e. from 6 to 20 at.\% (average 12.4 at.\%), and with mostly smaller esd's. These $\Delta$ Al's are also proportional to the $\Delta \mathrm{Y}_{\text {calc }}$ values (Appendix 8). Differences of the average octahedral $\langle Y-O\rangle$ and distances are in very good agreement between each other and mostly proportional to the $\mathrm{Fe}^{3+}$ and $\mathrm{Al}^{3+}$ contents (Fig. 7) and $\Delta$ Al's. These distances are: for $\langle Y-O\rangle$ from 0.05 to $0.14 \AA$ (average $0.09(2) \AA$ ) and from 0.02 to $0.04 \AA$ (average $0.03(3) \AA$ ), and for from 0.06 to $0.19 \AA$ (average $0.12(3) \AA$ ) and from 0.02 to $0.06 \AA$ (average $0.04(4) \AA$ ) for the $R 3 c$ and $F d d d$ space groups, respectively. Further, calculated degrees of ordering $(m)$ and intersite distribution coefficients $\left(K_{1-2}\right)$ are also concordant with each other and proportional to the other previously determined parameters. These parameters are: for $m$ from 0.037 to 0.192 (average 0.104 ) and from 0 to 0.032 (average 0.020 ), and for $K_{1-2}$ from 1.294 to 2.253 (average 1.765) and from 1 to 1.312 (average 1.156) for the $R 3 c$ and Fddd space groups, respectively. Variations in the $\Delta \mathrm{Al}, m$ and $K_{1-2}$ do not correlate well with the compositions of the zones studied for the Fddd space group, in concordance with the observations by Shtukenberg et al. (2005). However, it is interesting that such variations are mostly proportional (except for zone D) for the $R 3 c$ space group (Appendix 10). Finally, the $R_{\mathrm{B}}$ and $R_{\mathrm{F}}$ factors are mostly smaller in $R-3 c$ than for the $F d d d$ space group (Appendix 1). Therefore, all of the results given reasonably indicate that ferric grossular garnet studied crystallized in the rhombohedral $R 3 c$ space group (Fig. 8), supporting our previous results (Tančić et al., 2020).

\section{POLYHEDRAL DISTORTIONS AND STRUCTURAL DISORDERING BETWEEN THE ZONES STUDIED}

Average determined selected distances without constraints (Appendix 6) were analyzed and compared with the expected ones, i.e. according to their chemical compositions (Appendix 2). It can be seen as follows: (1) $<\mathrm{Si}-\mathrm{O}>$ distances are shorter in zones $A$ and $C$, longer in zone $B$, and adequate in zones $\mathrm{D}$ and $\mathrm{E} ;(2)<\mathrm{Y}-\mathrm{O}>$ distances are longer in zones $\mathrm{A}, \mathrm{C}$ and $\mathrm{E}$, and adequate in zones $\mathrm{B}$ and $\mathrm{D}$; and $(3)<X-O\rangle$ distances are shorter only in zone $B$, and adequate in all of the other zones.

Also, as shown by Tančić et al. (2012b), the shift of the cation and oxygen sites could be of special interest. For example, oxygen $\mathrm{O} 4$ is very significant in our case, because it is common to the Si tetrahedron, $Y 1$ octahedron and $X 2$ dodecahedron. From Appendix 11 it can be seen that the $\mathrm{Si}-\mathrm{Y} 1$ and $\mathrm{Si}-\mathrm{X} 2$ distances determined mostly increase from zone $A$ to zone $D$, and then decrease in zone $\mathrm{E}$. This is in a very good agreement with the chemical compositions of the zones, because they follow the $\mathrm{Al}-\mathrm{Fe}^{3+}$ substitutions at the octahedral site (Tančić et al., 2012a). On the other hand, $Y 1-X 2$ distances are in disagreement with previous observations, because they decrease as $A>C>E>D>B$. Also, from Appendix 6 it can be seen that the oxygen $\mathrm{O} 4$ site is most shifted towards $\mathrm{Si}$ and away from $\mathrm{Y} 1$ and $X 2$ sites in zones $\mathrm{A}$ and $\mathrm{C}$. Namely, $<\mathrm{Si}-\mathrm{O} 4>$ distances increase as $\mathrm{C}<\mathrm{A}<\mathrm{E}<\mathrm{B}<\mathrm{D}$, whereas $<\mathrm{Y} 1-\mathrm{O} 4>$ and $<X 2-\mathrm{O} 4>$ distances mostly decrease in the opposite direction, i.e. as $\mathrm{C}>\mathrm{A}>\mathrm{E}>\mathrm{B}=\mathrm{D}$ and $\mathrm{C}>\mathrm{A}>\mathrm{E}>\mathrm{D}>\mathrm{B}$, respectively.

Therefore, the largest deviations were determined in the $A$ and $C$ zones, which also have the highest declinations from the Grs-Adr joins (Fig. 7). As argued by Tančić et al. (2020), such discrepancies occurred between the determined and expected 
Comparison of the Diamantina, Meka Presedla and Munam ferric grossular garnet specimens

\begin{tabular}{|c|c|c|c|c|c|c|c|c|c|}
\hline & \multicolumn{2}{|c|}{ Space group } & $<\mathrm{Si}-\mathrm{O}>$ & $<Y-O>$ & Al sof & $<X-\mathrm{O}\rangle$ & Ca sof & $<D-O>$ & $<_{\mathrm{r}\{x\}}>/<_{\mathrm{r}[y]}>$ \\
\hline Diamantina & \multicolumn{2}{|c|}{$1 a^{-} 3 d$} & $1.642(2)$ & $1.970(2)$ & $66.9(8)$ & $2.410(2)^{a}$ & 100 & $2.108(2)^{a}$ & n. c. \\
\hline \multirow{5}{*}{$\begin{array}{l}\text { Meka } \\
\text { Presedla }\end{array}$} & \multirow{5}{*}{$R^{-} 3 c$} & A & $1.637(6)$ & $1.964(4)$ & $64(2)$ & $2.416(5)$ & 98 & $2.108(5)$ & 1.942 \\
\hline & & B & $1.658(6)$ & $1.960(4)$ & $61(6)$ & $2.405(5)$ & 98 & $2.107(5)$ & 1.938 \\
\hline & & $\mathrm{C}$ & $1.631(6)$ & $1.975(4)$ & $60(3)$ & $2.417(5)$ & 98 & $2.110(5)$ & 1.927 \\
\hline & & $\mathrm{D}$ & $1.644(6)$ & $1.973(4)$ & $58(2)$ & $2.414(5)$ & 98 & $2.111(5)$ & 1.921 \\
\hline & & $E$ & $1.643(6)$ & $1.971(4)$ & $58(6)$ & $2.412(5)$ & 98 & $2.110(5)$ & 1.923 \\
\hline Munam & \multicolumn{2}{|c|}{$\Gamma 1$} & $1.647(5)^{a}$ & $1.959(5)^{a}$ & 67 & $2.413(5)^{\mathrm{a}}$ & 97 & $2.108(5)^{a}$ & 1.948 \\
\hline
\end{tabular}

Distances are given in $\AA ; A$ Al and Ca sof's in at. \%; $\langle D-O\rangle=\{\langle\mathrm{Si}-\mathrm{O}\rangle+\langle Y-\mathrm{O}\rangle+2 \times\langle X-\mathrm{O}\rangle\} / 4 ;{ }^{a}-$ Tančić et al. (2020); n. c. not calculated

distances, and also Al and Ca sof's, and should be treated as a consequence of a non-cubic space group of crystallization polyhedral distortions and/or crystal disordering, because the $<D-\mathrm{O}>$ distances determined are within the expected ones in all of the zones studied. That being true, these distances become more adequate after constraints are applied and they return to the more "regular" positions (Appendices 2, 6 and 12) On the other hand, all of the average determined selected $<\mathrm{O}-\mathrm{Si}-\mathrm{O}\rangle,\langle\mathrm{O}-\mathrm{Y}-\mathrm{O}\rangle$ and $\langle\mathrm{O}-\mathrm{X}-\mathrm{O}\rangle$ angles (with and without constraints) are almost the same throughout the zones, and consistent with the expected ones (Appendix 7).

Because of the previously observed discrepancies, which deviate from the expected ones, especially in zones $\mathrm{A}$ and $\mathrm{C}$, polyhedral volumes, quadratic elongations and angle variances in the tetrahedron and two octahedra (Robinson et al., 1971), were calculated and are given in Appendix 13. From the results, the discrepancies are generally more explicit without than those with constraints, as expected. Also, octahedron-1 is mostly more distorted than octahedron-2, except for zone B. Polyhedral volumes of the tetrahedron and two octahedra are in concordance with the average $\langle\mathrm{Si}-\mathrm{O}\rangle,\langle\mathrm{O}-\mathrm{O}\rangle_{\text {tet }},\langle\mathrm{Y}-\mathrm{O}\rangle$ and $\langle\mathrm{O}-\mathrm{O}\rangle_{\text {oct }}$ distances throughout the zones (Appendix 6). Other results obtained also strongly indicate that distortions of the tetrahedron and octahedra indeed occurred to varying degrees, and influenced the deviations within the crystal structure Namely, quadratic elongations and angle variances in the tetrahedron decrease in the following order among the zones: $\mathrm{C}>\mathrm{A}>\mathrm{D}>\mathrm{B}>\mathrm{E}$; whereas, in octahedron-1, they decrease as $C>A>D>E>B$. Such orders are inversely proportional to the differences determined between $\beta_{0}$ (or $\gamma_{0}$ ) and $90^{\circ}$ in the $\Gamma 1$ space group (Appendix 1). In this way, it is demonstrated that the $A$ and $\mathrm{C}$ zones can be treated as disordered, whereas $\mathrm{B}, \mathrm{D}$ and $\mathrm{E}$ may be treated as more or less ordered. Such variations between the zones could be further presented as two different hypothetical models, i.e. as (pseudo)cyclical of an oscillatory nature, or even as some kind of (pseudo)rotational or spiral (Appendix 14; see also Milke, 2004).

Notably, the $R$-values obtained are obviously not in concordance with the order-disorder variations determined, because their highest values are in the A, B and D, and lowest in the C and $\mathrm{E}$ zones (Table 1, Appendices 1 and 4 ). To explain this, further experiments are necessary, which is beyond the scope of this paper. Likewise, it is obvious that such order-disorder variations are not caused by the chemical compositions of the zones and $\mathrm{Al}^{3+}-\mathrm{Fe}^{3+}$ substitutions at the octahedral sites, but most probably to the formation conditions, which will be further analysed here.
As previously shown by Tančić et al. (2020), there are only two ferric grossular samples found in the available literature, which have very similar chemical compositions to our sample. These are $\mathrm{Grs}_{60} \mathrm{Adr}_{38}-\mathrm{Grs}_{67} \mathrm{Adr}_{33}$ from Diamantina, Brazil (cubic la $3 d$ space group, Resende and Fernandes, 2005), and $\mathrm{Grs}_{67} \mathrm{Adr}_{33}$ from Munam, North Korea (triclinic $\Gamma 1$ space group, Takéuchi et al., 1982). However, these three ferric grossular garnets are obviously structurally very different between each other, as all of them crystallize not only in different space groups, but also in different crystallographic systems. The declinations between the Diamantina, Meka Presedla and Munam specimens are also visible by comparison of their $\langle\mathrm{Si}-\mathrm{O}\rangle$, $\langle Y-\mathrm{O}\rangle,\langle X-\mathrm{O}\rangle$ and $\langle D-\mathrm{O}\rangle$ distances, shown in Table 2 and Figure 9. From these results, the Diamantina and Meka Presedla specimens seem more disordered than that from Munam. This is not surprising, as symmetry increase, whereas ordering and birefringence decrease, with temperature increase (Allen and Busseck, 1988). The Meka Presedla and Munam specimens are from skarns, whereas for Diamantina the garnet's origin was not stated by Resende and Fernandes (2005); this limited our opportunities for some additional comparisons between them.

Finally, if we consider that heating of Grs up to $750^{\circ} \mathrm{C}$ causes the average $\langle X-\mathrm{O}\rangle$ and $\langle\mathrm{Al}-\mathrm{O}\rangle$ distances to increase (Meagher, 1975), and implement this possibility to the determined average $\langle X 2-04\rangle$ and $\langle Y 1-O 4\rangle$ distances (Appendix 6 ), then we can conclude that zones $C$ and $A$ were formed at higher temperatures than zones E, B and D. These two zones are closer to the cubic region of crystallization, and consequently with the lowest differences between $\beta_{0}$ (or $\gamma_{0}$ ) and $90^{\circ}$. Such temperature variations between the zones may also be inferred as cyclical or oscillatory (see Appendix 14A).

However, if the zones $C$ and $A$ were formed at higher temperatures, beside of the polyhedral distortions and order-disorder variations already established, the hypothetical possibility that some part of the thermally generated vacancies replaced $\mathrm{Si}$ in the tetrahedron cannot be excluded. Namely, the lack of boron (Tančić et al., 2012a), and shorter $\langle\mathrm{Si}-\mathrm{O}\rangle$ and $\langle\mathrm{O}-\mathrm{O}\rangle_{\text {tet }}$ distances, and smaller polyhedral volumes in the tetrahedron (even with applied constraints), could reasonably indicate such a possibility. Similarly, some part of $\mathrm{Al}^{3+}$ or $\mathrm{Fe}^{3+}$ could replace $\mathrm{Si}$ in the tetrahedron at zone $\mathrm{B}$, because of the longer $\langle\mathrm{Si}-\mathrm{O}\rangle$ and tet distances, and larger polyhedral volumes in the tetrahedron (Table 2 and Appendices 2, 6 and 13), which were not previously established with the EMPA measurements and calculations applied (Tančić et al., 2012a). 


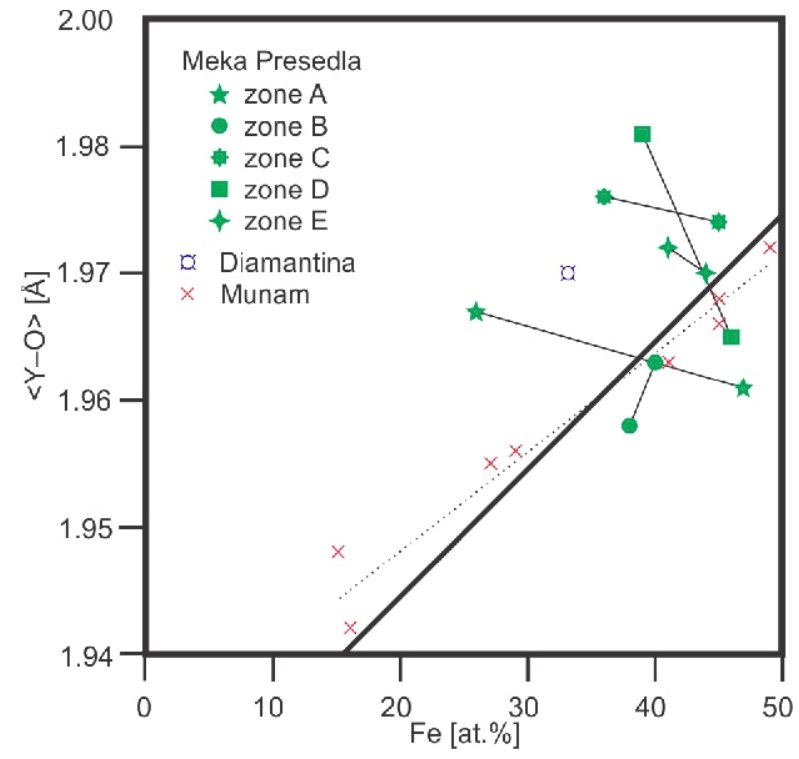

Fig. 9. Comparison of $\mathrm{Fe}^{3+}$ and $\mathrm{Al}^{3+}$ variations over the octahedral sites by the octahedral average $\langle Y-O\rangle$ distances for the Meka Presedla rhombohedral $R^{-} 3 c$ space group (green), Diamantina cubic $l a^{-} 3 d$ space group (blue), and Munam triclinic $\Gamma 1$ space group (red) ferric grossular garnets

The linear Grs-Adr join (Novak and Gibbs, 1971) was also plotted for comparison

\section{CONCLUSIONS}

Although Rietveld crystal structure refinement has some disadvantages in comparison with single-crystal X-ray diffraction (SCXRD) and other methods, the results described here and by Tančić et al. (2020) indicate that there is sufficient reliable evidence showing that the ferric grossular garnet crystallized in the rhombohedral $R^{-} 3 c$ space group. However, one could reasonably ask if this is possible. To the best of our knowledge, there is no published physical or other reliable evidence for grossular-andradite garnet that crystallizes in the rhombohedral crystal structure. Furthermore, there is no such evidence for any of the natural garnet subgroup member (Grew et al., 2013).

On the other hand, much evidence supports a rhombohedral crystal structure for this ferric grossular garnet, such as:

1. nikmelnikovite $\left(\mathrm{Ca}_{12} \mathrm{Fe}^{2+} \mathrm{Fe}^{3+}{ }_{3} \mathrm{Al}_{3}\left(\mathrm{SiO}_{4}\right)_{6}(\mathrm{OH})_{20}\right)$, is the first IMA-approved member of the garnet supergroup which crystallizes in the rhombohedral $R-3$ space group (Krivovichev et al., 2021);

2. there are some already known synthetic garnets which crystallize in the rhombohedral $R \quad 3 c$ and $R 3$ space groups, such as $\mathrm{Ho}_{3} \mathrm{Fe}_{5} \mathrm{O}_{12}$ (Guillot et al., 1984), $\mathrm{Y}_{3} \mathrm{Fe}_{5} \mathrm{O}_{12}$ (Rodić et al., 1999) and $\mathrm{R}_{3} \mathrm{Fe}_{5} \mathrm{O}_{12}$ with $\mathrm{R}=\mathrm{Y}$, Eu and Dy (Vandormael et al., 2001);

3. $R-3 c$ is a subgroup of the la $^{-} 3 d$ space group;

4. $R 3 c$ is one of the possibilities of the $T_{2 g}$ route, i.e. a phase transition from $\mathrm{Ia}^{-} 3 d$ to the $R-3 c, \mathrm{Fddd}, \mathrm{C} 2 / \mathrm{c}$ and $\Gamma 1$ space groups (Hatch and Griffen, 1989), which is consistent to the chemical composition of the ferric grossular garnet studied (Tančić et al., 2012a, 2020);

5. only the rhombohedral $R 3 c$ and $R 3$ space groups satisfied both possible geometrical-mathematical conditions, i.e. following transformations of the cubic symmetry axis: (a) $a_{0 \text { rhomb }}=a_{0 \text { cubic }} \times \mathrm{v} 3 / 2=\sim 10.32 \AA$ and $(\mathrm{b})$ $c_{\text {Orhomb }}=a_{\text {ocubic }} \times \mathrm{v} 2=\sim 16.86 \AA$ (Tančić et al., 2020);

6. among three determined or calculated crystallographic axes, two are quite similar, whereas the third is significantly different, indicating the rhombohedral crystal system (Appendix 1);

7. observed departures of the calculated rhombohedral distortion angles $\alpha$ from $60^{\circ}$ (Appendix 1);

8. the degree of ordering $(m)$ and intersite distribution coefficient $\left(K_{1-2}\right)$ determined for the Fddd space group (Appendix 9 ) are the lowest among all those determined for the Fddd and $\Gamma 1$ space groups (Shtukenberg et al., 2005);

9. differences in sof's decrease with an increase in temperature (Shtukenberg et al., 2005). Accordingly, the crystallization temperature of the ferric grossular garnet studied should be higher than required for the Fddd space group, because of their insignificant $\Delta$ Al's;

10. it is well known that symmetry increases with increasing temperature, and the preferred crystal structure symmetry is governed by the crystallization temperature;

11. Milke (2004) suggests that an ordering process which relates to the birefringence in intermediate and Grs-rich grossular-andradites seems to be largely controlled by the growth temperature, whereas chemical composition, growth medium, and pressure are only minor factors. He obtained a temperature of $730^{\circ} \mathrm{C}$ between birefringent and isotropic $\mathrm{Grs}_{76-99} \mathrm{Adr}_{1-24}$ samples. Also, Hariya and Kimura (1978) found a transition from anisotropic to isotropic $\mathrm{Grs}_{50} \mathrm{Adr}_{50}$ grossular-andradite at temperatures slightly below $700^{\circ} \mathrm{C}$, with a tendency to lower temperatures at higher pressure. According to Shtukenberg et al. (2005), the transformation from the orthorhombic to the triclinic crystal structure occurs in the range $150-350^{\circ} \mathrm{C}$. Crystallization at elevated temperatures leads to a more symmetric orthorhombic crystal structure. Therefore, it can be concluded that a rhombohedral crystal structure could be possible in the temperature range somewhere between the orthorhombic and cubic systems. Previously obtained formation temperatures between $\sim 600$ and $720^{\circ} \mathrm{C}$ (Tančić et al., 2012a) of the $\mathrm{Grs}_{58-64} \mathrm{Adr}_{36-41} \mathrm{Sps}_{2}$ ferric grossular garnet studied in this paper, just below those required for cubic symmetry, could sufficiently satisfy such a condition.

Besides the rhombohedral symmetry determined, which could be treated as a primary cause for its slight optical anisotropy, residual strain may be also treated as the second possible cause, due to the chemical, structural, order-disorder and formation differences recognized between the zones.

Acknowledgements. This paper is dedicated to the memory of our dear friend and colleague, Dr. Predrag Vulić †(1973-2020), Professor at the Laboratory of Crystallography, Faculty of Mining and Geology, University of Belgrade. This research did not receive any specific grant from funding agencies in public, commercial or not-for-profit sectors. 


\section{REFERENCES}

Allen, F.M., Buseck, P.R., 1988. XRD, FTIR and TEM studies of optically anisotropic grossular garnets. American Mineralogist, 73 568-584.

Badar, M.A., Hussain, S., Niaz, S., Rehman, S.U., 2016. Anomalous optical variations in the grossular garnet from the Eden Mills, Belvidere Mountain (Vermont, USA). Arabian Journal of Geosciences, 9: 545

Berar, J.F., Lelann, P., 1991. E.S.D.'s and estimated probable error obtained in Rietveld refinements with local correlations. Journal of Applied Crystallography 24: 1-5.

Cvetković, Ž., Tančić, P., 2019. Mineralogical and crystallographic characteristics of bauxites from some Grebnik's (Metohija, Serbia) ore deposits. Geološki anali Balkanskoga poluostrva, $\mathbf{8 0}$ 45-61.

Deer, W., Howie, R., Zussman, J., 2013. Garnet Group. In: An Introduction to the Rock-Forming Minerals, 3rd ed.: 18-27. The Mineral Society, London.

Frank-Kamenetskaya, O.V., Rozhdestvenskaya, I.V., Shtukenberg, A.G., Bannova, I.I., Skalkina, Yu.A., 2007 Dissymmetrization of crystal structures of grossular-andradite garnets $\mathrm{Ca}_{3}(\mathrm{Al}, \mathrm{Fe})_{2}\left(\mathrm{SiO}_{4}\right)_{3}$. Structural Chemistry, 18: 493-500.

Gali, S., 1984. Reduction of symmetry in grandite solid solution. Acta Geologica Hispanica 19: 287-293.

Grew, E.S., Locock, A.J., Mills, S.J., Galuskina, I.O., Galuskin, E.V., Hålenius, U., 2013. IMA Report, nomenclature of the garnet supergroup. American Mineralogist, 98: 785-811.

Guillot, M., Tchéou, F., Marchand, A., Feldman, P., 1984. Temperature evolution of the umbrella structure in holmium iron garnet. Zeitschrift für Physik B Condensed Matter, 56: 29-39.

Hariya, Y., Kimura, M., 1978. Optical anomaly garnet and its stability field at high pressures and temperatures. Journal of the Faculty of Sciences, Hokkaido University, Series IV(18): 611-624.

Hatch, D.M., Griffen, D.T., 1989. Phase transitions in the grandite garnets. American Mineralogist, 74: 151-159.

Hirai, H., Nakazawa, H., 1986. Visualising low symmetry of a grandite garnet on precession photographs. American Mineralogist, 71: 1210-1213.

Ishizawa, N., Inagaki, Y., 2008. A Guide to Discriminating the Rhombohedral Cell from the Face-Centred Pseudo Cubic Cell, Ceramics Research Center, Annual Report, 8: 35-49.

Kingma, K.J., Downs, J.W., 1989. Crystal-structure analysis of a birefringent andradite. American Mineralogist, 74: 1307-1316.

Kobayashi, S., Miyawaki, R., Momma, K., Fujisawa, A., Kaneda, H., 2013. Anisotropic garnet from the Yamansu ore deposit, Xinjiang, China. Journal of Mineralogical and Petrological Sciences, 108: 245-254.

Kostić, B., Srećković-Batoćanin, D., Filipov, P., Tančić, P., Sokol, K., 2021. Anisotropic grossular-andradite garnets: Evidence of two stage skarn evolution from Rudnik, Central Serbia. Geologica Carpathica, 73: 17-25.

Krivovichev, S.V., Panikorovskii, T.L., Yakovenchuk, V.N., Selivanova, E.A., Ivanyuk, G.Yu., 2021. Trigonal variation in the garnet supergroup: the crystal structure of nikmelnikovite $\mathrm{Ca}_{12} \mathrm{Fe}^{2+} \mathrm{Fe}^{3+}{ }_{3} \mathrm{Al}_{3}\left(\mathrm{SiO}_{4}\right)_{6}(\mathrm{OH})_{20}$, from Kovdor massif, Kola Peninsula, Russia. Mineralogical Magazine, prepublished article.

Meagher, E.P., 1975. The crystal structures of pyrope and grossularite at elevated temperatures. American Mineralogist, 60: $218-228$.

Milke, R., 2004. Spiral growth of grossular under hydrothermal conditions. American Mineralogist, 89: 211-218.
Nakamura, Y., Kuribayashi, T., Nagase, T., 2016. Cation ordering of $\{110\}$ and $\{211\}$ sectors in grandite from Mali. Journal of Mineralogical and Petrological Sciences, 108: 245-254.

Novak, G.A., Gibbs, G.V., 1971. The crystal chemistry of the silicate garnets. American Mineralogist, 56: 791-825.

Program plotCIF (Computer software): http://publcif.iucr.org/services/tools/pdcifplot.php

Resende, J.A.L.C., Fernandes, N.G., 2005. X-ray powder refinement of a natural garnet from Diamantina, Minas Gerais, Brazil. Acta Crystallographica, E61: 265-267.

Rodić, D., Mitrić, M., Tellgren, R., Rundlof, H., Kremenović, A., 1999. True magnetic structure of the ferromagnetic garnet $\mathrm{Y}_{3} \mathrm{Fe}_{5} \mathrm{O}_{12}$ and magnetic moments of iron ions. Journal of Magnetism and Magnetic Materials, 191: 137-145.

Rodriguez-Carvajal, J., 1990. Program Fullprof (Computer software), Abstract of 15th Conference of International Union of Crystallography, Satellite Meeting on Powder Diffraction, 127, Toulouse, France.

Rossmanith, E., Armbruster, T., 1995. The intensity of forbidden reflections of pyrope: Umweganregung or symmetry reduction? Zeitschrift für Kristallographie, 210: 645-649.

Sherriff, B.L., Sokolova, E.V., Kabalov, Y.K., Jenkins, D.M., Kunath-Fandrei, G., Goetz, S., Jager, C., Schneider, J., 2000. Meionite: Rietveld structure-refinement, $\mathrm{Si}$ MAS and $\mathrm{Al}$ SATRAS NMR spectroscopy, and comments on the marialite-meionite series. Canadian Mineralogist, 38 1201-1213.

Shtukenberg, A.G., Popov, D.Yu., Punin, Yu.O., 2005. Growth ordering and anomalous birefringence in ugrandite garnets. Mineralogical Magazine, 69: 537-550.

Srećković-Batoćanin, D., Vasković, N., Milutinović, S., Ilić, V., Nikić, Z., 2014. Composition of zonal garnets from the garnetite exo-skarn of the ore field Rogozna (Rogozna Mts, southern Serbia). Proceedings of the XVI Serbian Geological Congress, Donji Milanovac: 265-269.

Takéuchi, Y., Haga, N., Umizu, S., Sato, G., 1982. The derivative structure of silicate garnets in grandite. Zeitschrift für Kristallographie 158: 53-99.

Tančić, P., Vulić, P., Kaindl, R., Sartory, B., Dimitrijević, R. 2012a. Macroscopically-zoned grandite from the garnetite skarn of Meka Presedla (Kopaonik Mountain, Serbia). Acta Geologica Sinica, 86: 393-406.

Tančić, P., Dimitrijević, R., Poznanović, M., Pačevski, A., Sudar, S., 2012b. Crystal structure and chemical composition of ludwigite from Vranovac ore deposit (Boranja Mountain, Serbia), Acta Geologica Sinica, 86: 1524-1538.

Tančić, P., Kremenović, A., Vulić, P., 2020. Structural dissymmetrization of optically anisotropic $\mathrm{Grs}_{64{ }_{1} 1} \mathrm{Adr}_{36{ }_{11}} \mathrm{Sps}_{2}$ grandite from Meka Presedla (Kopaonik Mt., Serbia). Powder Diffraction, 35: 7-16.

Vandormael, D., Grandjean, F., Hautot, D. Long, G.J., 2001. Mössbauer spectral evidence for rhombohedral symmetry in R3Fe5O12 garnets with $\mathrm{R}=\mathrm{Y}$, Eu and Dy. Journal of Physics: Condensed Matter, 13: 1759-1772.

Warr, L.N., 2021. IMA-CNMNC approved mineral symbols. Mineralogical Magazine, 85: 291-320

Wehrenberg, J.P., 1971. The infrared spectra of scapolite. American Mineralogist, 56: 1639-1654.

Whitney, D.L., Evans, B.W., 2010. Abbreviations for names of rock-forming minerals. American Mineralogist, 95: 185-187. 


\section{APPENDIX 1}

Unit cell dimensions, calculated $\mathrm{Ca}$ and $\mathrm{Al}$ sof's (in at.\%), and $\boldsymbol{R}_{\mathrm{B}}$ and $\boldsymbol{R}_{\mathrm{F}}$ reliability factors (in \%) for the studied six space groups without constraints

\begin{tabular}{|c|c|c|c|c|c|c|}
\hline Space g. & & $\mathrm{A}$ (core) ${ }^{1}$ & B & C & $\mathrm{D}$ & E (rim) \\
\hline \multirow{10}{*}{$1 a \overline{3} d$} & SCOR & 2.3375 & 2.4607 & 2.0808 & 2.0659 & 1.7162 \\
\hline & $a_{0}(\AA)$ & $11.9188(6)^{*}$ & $11.9320(8)$ & 11.9342(5) & 11.9342(8) & $11.9287(6)$ \\
\hline & $V_{0}\left(\AA^{3}\right)$ & 1693.2(1) & $1698.8(2)$ & $1699.7(1)$ & 1699.7(2) & $1697.4(1)$ \\
\hline & $a_{0} \times \sqrt{3} / 2(\AA)$ & 10.3220 & 10.3334 & 10.3353 & 10.3353 & 10.3306 \\
\hline & $a_{0} \times \sqrt{2}(\AA)$ & 16.8557 & 16.8744 & 16.8775 & 16.8775 & 16.8697 \\
\hline & $\mathrm{Ca}$ & $78(5)$ & $96(1)$ & $79(1)$ & $98(4)$ & $97(4)$ \\
\hline & $\mathrm{Al}$ & $84(1)$ & $65(1)$ & $70(1)$ & 59(1) & $58(1)$ \\
\hline & $\mathrm{Al}_{\text {calc }}$ & 66 & 60 & 59 & 59 & 61 \\
\hline & $R_{\mathrm{B}}$ & 9.23 & 8.87 & 6.57 & 7.98 & 6.82 \\
\hline & $R_{\mathrm{F}}$ & 7.69 & 7.20 & 6.51 & 6.89 & 5.83 \\
\hline \multirow{14}{*}{$R \overline{3 c}$} & SCOR & 2.1962 & 2.3374 & 1.8919 & 1.8017 & 1.6553 \\
\hline & $a_{0}(\AA)$ & $16.852(1)$ & 16.861(1) & 16.8824(9) & $16.873(2)$ & $16.8615(9)$ \\
\hline & $c_{0}(\AA)$ & $10.3252(9)$ & $10.341(1)$ & $10.3308(8)$ & $10.338(1)$ & $10.3386(7)$ \\
\hline & $V_{0}\left(\AA^{3}\right)$ & $2539.4(3)$ & $2547.8(5)$ & $2549.9(3)$ & $2548.7(5)$ & $2545.6(2)$ \\
\hline & $4 \times c_{0} / a_{0}$ & 2.45080 & 2.45324 & 2.44771 & 2.45078 & 2.45259 \\
\hline & $\alpha\left(^{\circ}\right)$ & 59.976 & 59.932 & 60.032 & 59.976 & 59.944 \\
\hline & Ca1 & $100(4)$ & $94(6)$ & $100(4)$ & 102(2) & 98(4) \\
\hline & $\mathrm{Ca} 2$ & $80(20)$ & 96(4) & $78(12)$ & $96(2)$ & $96(14)$ \\
\hline & $<$ Ca $>$ & $90(12)$ & $95(5)$ & $89(8)$ & 99(2) & 97(9) \\
\hline & Al1 & $78(12)$ & $54(18)$ & $54(12)$ & $66(6)$ & $42(12)$ \\
\hline & Al2 & $84(4)$ & $68(6)$ & $70(4)$ & $60(2)$ & $62(4)$ \\
\hline & $<\mathrm{Al}>$ & 81(8) & $61(12)$ & $62(8)$ & $63(4)$ & $52(8)$ \\
\hline & $R_{\mathrm{B}}$ & 8.17 & 8.64 & 6.07 & 6.78 & 6.02 \\
\hline & $R_{\mathrm{F}}$ & 6.80 & 7.42 & 6.31 & 6.94 & 6.24 \\
\hline \multirow{16}{*}{$R 3$} & SCOR & 2.1321 & 2.2775 & 1.8849 & 1.7886 & 1.6468 \\
\hline & $a_{0}(\AA)$ & $16.852(1)$ & $16.867(1)$ & $16.8713(8)$ & $16.872(2)$ & $16.874(1)$ \\
\hline & $c_{0}(\AA)$ & $10.3255(8)$ & 10.341(1) & $10.3416(7)$ & $10.338(1)$ & $10.326(1)$ \\
\hline & $V_{0}\left(\AA^{3}\right)$ & $2539.4(3)$ & $2547.7(4)$ & 2549.2(2) & 2548.7(5) & $2546.4(2)$ \\
\hline & $4 \times c_{0} / a_{0}$ & 2.45087 & 2.45236 & 2.45188 & 2.45092 & 2.44779 \\
\hline & $\alpha\left(^{\circ}\right)$ & 59.974 & 59.946 & 59.956 & 59.974 & 60.030 \\
\hline & Ca1 & $110(20)$ & 94(7) & $110(20)$ & $100(20)$ & $110(20)$ \\
\hline & Ca2 & $70(20)$ & 96(5) & $80(20)$ & $96(3)$ & $100(20)$ \\
\hline & $<$ Ca $>$ & $90(20)$ & $95(6)$ & $95(20)$ & $98(12)$ & $105(20)$ \\
\hline & Al1 & $78(36)$ & $60(36)$ & $54(24)$ & $60(42)$ & $42(36)$ \\
\hline & $\mathrm{Al} 2$ & $78(36)$ & $48(36)$ & $66(36)$ & $66(36)$ & $60(36)$ \\
\hline & $\mathrm{Al} 3$ & $80(20)$ & $70(14)$ & $66(16)$ & $58(18)$ & $58(18)$ \\
\hline & Al4 & $80(20)$ & $70(14)$ & $72(14)$ & $66(18)$ & $72(16)$ \\
\hline & $<\mathrm{Al}>$ & $79(28)$ & $62(25)$ & $64(22)$ & $62(28)$ & $58(26)$ \\
\hline & $R_{\mathrm{B}}$ & 7.69 & 8.48 & 6.23 & 6.75 & 6.12 \\
\hline & $R_{\mathrm{F}}$ & 6.58 & 7.69 & 6.64 & 7.11 & 5.77 \\
\hline \multirow{15}{*}{ Fddd } & SCOR & 2.2850 & 2.3749 & 1.8482 & 1.8893 & 1.6218 \\
\hline & $a_{0}(\AA)$ & $16.874(1)$ & $16.895(2)$ & $16.895(1)$ & $16.861(2)$ & $16.892(1)$ \\
\hline & $b_{0}(\AA)$ & $16.849(1)$ & $16.863(2)$ & $16.873(1)$ & $16.8919(9)$ & $16.860(1)$ \\
\hline & $c_{0}(\AA)$ & 11.9137(7) & $11.927(1)$ & 11.9292(7) & 11.922(1) & 11.9253(7) \\
\hline & $V_{0}\left(\AA^{3}\right)$ & $3387.2(4)$ & $3398.1(7)$ & $3400.7(4)$ & $3395.6(5)$ & $3396.4(4)$ \\
\hline & $c_{0} \times \sqrt{2}(\AA)$ & 16.8485 & 16.867 & 16.8704 & 16.860 & 16.8649 \\
\hline & Ca1 & $88(8)$ & 96(8) & 92(8) & 92(8) & 112(8) \\
\hline & $\mathrm{Ca} 2$ & 104(12) & $88(8)$ & $84(8)$ & 104(4) & $108(8)$ \\
\hline & Ca3 & 109(3) & 98(3) & $113(2)$ & 98(2) & $95(2)$ \\
\hline & $<\mathrm{Ca}>$ & $100(8)$ & $94(6)$ & $96(6)$ & $98(5)$ & 105(6) \\
\hline & Al1 & $80(8)$ & $66(10)$ & $66(8)$ & $66(6)$ & $64(8)$ \\
\hline & $\mathrm{Al} 2$ & $84(8)$ & $66(10)$ & $68(8)$ & $62(4)$ & $60(8)$ \\
\hline & $<\mathrm{Al}>$ & $82(8)$ & $66(10)$ & $67(8)$ & $64(5)$ & $62(8)$ \\
\hline & $R_{\mathrm{B}}$ & 8.63 & 8.72 & 5.80 & 7.67 & 6.30 \\
\hline & $R_{\mathrm{F}}$ & 7.39 & 7.65 & 6.06 & 7.54 & 6.22 \\
\hline \multirow{8}{*}{$C 2 / c$} & SCOR & 2.1433 & 2.0216 & 1.7629 & 1.7536 & 1.6051 \\
\hline & $a_{0}(\AA)$ & $16.861(2)$ & $16.894(4)$ & 16.8923(5) & $16.900(2)$ & $16.888(1)$ \\
\hline & $b_{0}(\AA)$ & 11.9205(6) & $11.951(2)$ & 11.9329(4) & $11.924(3)$ & 11.922(2) \\
\hline & $c_{0}(\AA)$ & 11.910(1) & $11.943(3)$ & 11.9432(4) & $11.945(3)$ & $11.943(2)$ \\
\hline & $\beta_{0}\left(^{\circ}\right)$ & $134.97(1)$ & $135.08(1)$ & $134.079(1)$ & $135.084(5)$ & $135.071(4)$ \\
\hline & $V_{0}\left(\AA^{3}\right)$ & 1693.5(3) & $1702.9(7)$ & $1699.9(1)$ & $1700.1(6)$ & $1698.2(4)$ \\
\hline & $a_{0} / \sqrt{2}(\AA)$ & 11.922 & 11.946 & 11.945 & 11.950 & 11.942 \\
\hline & Ca1 & 106(14) & $96(10)$ & $108(10)$ & 92(10) & $86(14)$ \\
\hline
\end{tabular}




\begin{tabular}{|c|c|c|c|c|c|c|}
\hline & Ca2 & $98(10)$ & $94(8)$ & 112(12) & $92(10)$ & $92(16)$ \\
\hline & Ca3 & $97(6)$ & $102(7)$ & $110(9)$ & 104(7) & 93(9) \\
\hline & $\mathrm{Ca} 4$ & 108(7) & $85(5)$ & $86(3)$ & 101(3) & $100(3)$ \\
\hline & $<\mathrm{Ca}>$ & 102(9) & $94(8)$ & 106(8) & $97(8)$ & $93(10)$ \\
\hline & Al1 & $100(20)$ & $58(14)$ & $60(20)$ & $60(20)$ & $60(20)$ \\
\hline & $\mathrm{Al} 2$ & $98(18)$ & $56(16)$ & $60(20)$ & $72(18)$ & $80(20)$ \\
\hline & $\mathrm{Al} 3$ & $120(20)$ & $80(14)$ & $60(20)$ & $60(20)$ & $60(20)$ \\
\hline & $\mathrm{Al} 4$ & $100(20)$ & $86(18)$ & $60(20)$ & $60(20)$ & $60(20)$ \\
\hline & $<\mathrm{Al}>$ & $104(20)$ & $70(16)$ & $60(20)$ & $63(20)$ & $65(20)$ \\
\hline & $R_{\mathrm{B}}$ & 7.54 & 7.30 & 6.73 & 6.25 & 5.33 \\
\hline & $R_{\mathrm{F}}$ & 6.48 & 6.95 & 8.38 & 7.03 & 5.53 \\
\hline \multirow{28}{*}{$I 1$} & SCOR & 2.7890 & 3.0879 & 2.2768 & 2.3167 & 1.7755 \\
\hline & $a_{0}(\AA)$ & $11.927(2)$ & $11.926(3)$ & $11.9467(8)$ & $11.941(2)$ & 11.931(1) \\
\hline & $b_{0}(\AA)$ & $11.910(2)$ & 11.945(2) & 11.931(1) & 11.925(2) & $11.9260(9)$ \\
\hline & $c_{0}(\AA)$ & 11.920(1) & $11.929(2)$ & $11.9303(8)$ & 11.928(2) & $11.940(1)$ \\
\hline & $<a_{0}(\AA)>$ & 11.919(2) & 11.933(2) & $11.9360(9)$ & 11.931(2) & 11.932(1) \\
\hline & $\alpha_{0}\left(^{\circ}\right)$ & $90.01(2)$ & $89.96(1)$ & $90.060(4)$ & $89.98(1)$ & $89.96(7)$ \\
\hline & $\beta_{0}\left(^{\circ}\right)$ & $90.081(9)$ & $90.04(1)$ & $90.007(5)$ & $90.11(1)$ & $90.12(5)$ \\
\hline & $Y_{0}\left({ }^{\circ}\right)$ & $89.98(2)$ & $89.89(1)$ & $89.922(4)$ & $89.94(1)$ & $90.03(6)$ \\
\hline & $V_{0}\left(\AA^{3}\right)$ & $1693.4(4)$ & 1699.3(5) & $1700.5(2)$ & 1698.5(4) & 1698.9(3) \\
\hline & $\beta_{0}-90\left(^{\circ}\right)$ & $0.081(9)$ & $-0.11(1)^{\#}$ & $-0.078(4)^{\#}$ & $0.11(1)$ & $0.12(5)$ \\
\hline & $\mathrm{Ca} 1$ & $120(50)$ & $100(50)$ & $110(20)$ & $110(20)$ & $100(20)$ \\
\hline & Ca2 & $100(30)$ & $100(30)$ & $110(30)$ & $80(20)$ & $100(20)$ \\
\hline & Ca3 & $90(20)$ & $90(30)$ & $90(20)$ & $90(20)$ & $80(10)$ \\
\hline & $\mathrm{Ca} 4$ & $110(50)$ & $100(40)$ & $110(20)$ & $100(20)$ & $90(20)$ \\
\hline & Ca5 & $110(20)$ & $100(40)$ & $110(30)$ & $100(20)$ & $100(20)$ \\
\hline & Ca6 & $100(30)$ & $90(30)$ & $90(20)$ & $100(20)$ & $90(20)$ \\
\hline & $<\mathrm{Ca}>$ & 105(33) & $97(37)$ & $103(23)$ & $97(20)$ & 93(18) \\
\hline & Al1 & $80(100)$ & $80(100)$ & $80(100)$ & $60(60)$ & $40(60)$ \\
\hline & $\mathrm{Al} 2$ & $80(80)$ & $60(80)$ & $80(80)$ & $80(80)$ & $60(80)$ \\
\hline & $\mathrm{Al} 3$ & $80(100)$ & $60(80)$ & $80(80)$ & $80(80)$ & $80(60)$ \\
\hline & $\mathrm{Al} 4$ & $80(80)$ & $60(100)$ & $80(80)$ & $80(80)$ & $60(60)$ \\
\hline & Al5 & $80(80)$ & $80(80)$ & $80(60)$ & $80(60)$ & $80(60)$ \\
\hline & Al6 & $80(120)$ & $60(80)$ & $80(60)$ & $80(60)$ & $60(80)$ \\
\hline & $\mathrm{Al} 7$ & $80(100)$ & $60(120)$ & $60(60)$ & $40(80)$ & $60(60)$ \\
\hline & $\mathrm{Al} 8$ & $80(80)$ & $60(120)$ & $80(60)$ & $60(60)$ & $80(80)$ \\
\hline & $<\mathrm{Al}>$ & $80(92)$ & $65(95)$ & $78(72)$ & $70(70)$ & $65(68)$ \\
\hline & $R_{\mathrm{B}}$ & 11.2 & 12.0 & 7.94 & 9.01 & 7.65 \\
\hline & $R_{\mathrm{F}}$ & 9.71 & 11.6 & 10.3 & 9.35 & 8.21 \\
\hline
\end{tabular}

Calculated $4 \times c_{0} / a_{0}$ parameters and distortion $\alpha$ angles for the rhombohedral $R \overline{3} c$ and $R \overline{3}$ space groups, and specific geometry-mathematical transformations of the crystallographic axes within la $3 d$, Fddd and $C 2 / c$ space groups, are also presented; * - the numbers in parentheses are the estimated standard deviations multiplied with SCOR and refer to the last significant number; ${ }^{1}-$ Tančić et al. (2020); ${ }^{*}-y_{0}-90\left[\left[^{0}\right]\right.$; for the triclinic $I^{1} 1$ space group, instead of 100 parameters for the background description, it was used 6 Chebyschev's polynomial parameters, and there were omitted $2 \theta$ region from $4^{\circ}$ to $10^{\circ}$ 


\section{APPENDIX 2}

Applied constraints for the $\mathrm{Ca}$ and $\mathrm{Al}$ sof's (in at.\%) and for the $\langle\mathrm{Si}-\mathrm{O}\rangle,\langle Y-\mathrm{O}\rangle,\langle X-\mathrm{O}\rangle$ and $\left\langle X^{\prime \prime}-\mathrm{O}\right\rangle$ distances (in $\AA$ )

\begin{tabular}{|c|c|c|c|c|c|}
\hline & $\mathrm{A}(\mathrm{core})^{1}$ & $\mathrm{~B}$ & $\mathrm{C}$ & $\mathrm{D}$ & $\mathrm{E}(\operatorname{rim})$ \\
\hline $\mathrm{Ca}$ & 98 & 98 & 98 & 98 & 98 \\
\hline $\mathrm{Al}$ & 64 & 62 & 59 & 58 & 58 \\
\hline$<\mathrm{Si}-\mathrm{O}>$ & $1.644(5)$ & $1.644(5)$ & $1.644(5)$ & $1.644(5)$ & $1.644(5)$ \\
\hline$<Y-\mathrm{O}>$ & $1.960(5)$ & $1.962(5)$ & $1.965(5)$ & $1.966(5)$ & $1.966(5)$ \\
\hline$<X-\mathrm{O}>$ & $2.336(5)$ & $2.336(5)$ & $2.337(5)$ & $2.338(5)$ & $2.338(5)$ \\
\hline$<X^{\prime \prime}-\mathrm{O}>$ & $2.494(5)$ & $2.494(5)$ & $2.494(5)$ & $2.494(5)$ & $2.494(5)$ \\
\hline$<D-\mathrm{O}>$ & $2.108(5)$ & $2.109(5)$ & $2.110(5)$ & $2.110(5)$ & $2.110(5)$ \\
\hline
\end{tabular}

${ }^{1}-$ Tančić et al. $(2020) ;\langle D-\mathrm{O}\rangle=\left\{\langle\mathrm{Si}-\mathrm{O}\rangle+\langle Y-\mathrm{O}\rangle+\langle X-\mathrm{O}\rangle+\left\langle X^{\prime \prime}-\mathrm{O}\right\rangle\right\} / 4$ 


\section{APPENDIX 3}

Variations of the cubic $a_{0}$ axis (la $\overline{3} d$ space group) by Raman shift of band

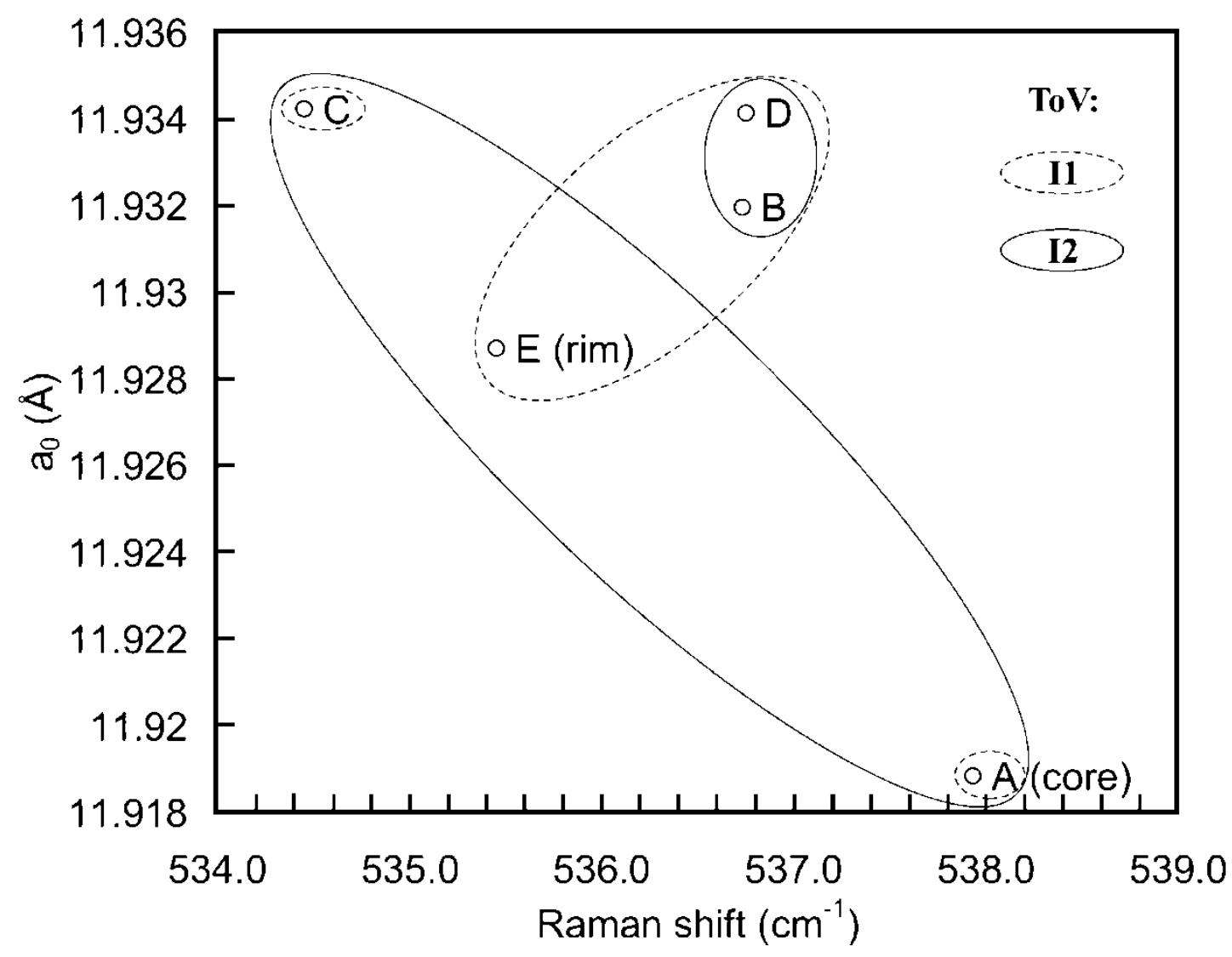

VIITwo types of variations (ToV) are clearly visible: (I) proportional for zones $\mathrm{B}, \mathrm{D}$ and $\mathrm{E}$, and declination from it at zones $\mathrm{A}$ and $C$, and (II) inversely proportional for zones $A, C$ and $E$, and declination from it at zones $B$ and $D$ 


\section{APPENDIX 4}

Profile and structural parameters, unit cell dimensions and reliability factors for the $\bar{R} \mathbf{3} c$ space group with constraints

\begin{tabular}{|c|c|c|c|c|c|c|}
\hline \multicolumn{2}{|c|}{ Zone } & $\mathrm{A}(\text { core })^{1}$ & $\mathrm{~B}$ & $\mathrm{C}$ & $\mathrm{D}$ & $E$ (rim) \\
\hline \multicolumn{2}{|l|}{ SCOR } & 2.4445 & 2.5216 & 2.2050 & 1.9755 & 1.7076 \\
\hline \multicolumn{2}{|c|}{ Overall scale f. $\left(\times 10^{-1}\right)$} & $60(3)^{n}$ & $75(4)$ & $70(3)$ & $130(20)$ & $41(1)$ \\
\hline \multicolumn{2}{|c|}{ Eta $(p-v)$ or $m(p-v i i)$} & $0.32(9)$ & $0.32(9)$ & $0.08(7)$ & $0.28(8)$ & $0.13(8)$ \\
\hline \multicolumn{2}{|c|}{ Overall temp. factor } & $0.3(1)$ & $0.4(1)$ & $0.50(8)$ & $0.8(1)$ & $0.51(8)$ \\
\hline \multirow{3}{*}{$\begin{array}{l}\text { Halfwidth } \\
\text { parameters }\end{array}$} & $\mathrm{U}$ & $0.020(7)$ & $0.06(1)$ & $-0.009(5)$ & $0.03(1)$ & $0.012(5)$ \\
\hline & $\mathrm{V}$ & $0.004(9)$ & $-0.03(1)$ & $0.031(8)$ & $0.03(1)$ & $-0.018(8)$ \\
\hline & $\mathrm{W}$ & $0.010(2)$ & $0.026(4)$ & $0.014(2)$ & $0.013(4)$ & $0.031(3)$ \\
\hline \multicolumn{2}{|c|}{ Preferred orientation } & $0.60(5)$ & $0.36(5)$ & $0.43(4)$ & $-0.68(7)$ & $0.25(3)$ \\
\hline \multirow{2}{*}{$\begin{array}{l}\text { Asymmetry } \\
\text { parameters }\end{array}$} & As 1 & $0.03(6)$ & $0.18(4)$ & $0.07(5)$ & $0.08(6)$ & $0.04(4)$ \\
\hline & As 2 & $0.048(8)$ & $0.066(7)$ & $0.053(7)$ & $0.044(7)$ & $0.038(6)$ \\
\hline \multicolumn{2}{|l|}{ X parameter } & $0.004(2)$ & $0.002(2)$ & $0.009(1)$ & $0.003(2)$ & $0.008(2)$ \\
\hline \multicolumn{2}{|l|}{ Zero-point } & $0.011(8)$ & $0.032(8)$ & $-0.001(7)$ & $0.02(1)$ & $-0.043(6)$ \\
\hline \multicolumn{2}{|l|}{$a_{0}(\AA)$} & 16.852(2) & $16.867(2)$ & $16.883(1)$ & $16.873(2)$ & $16.8611(9)$ \\
\hline \multicolumn{2}{|l|}{$c_{0}(\AA)$} & 10.326(1) & $10.341(2)$ & $10.3304(8)$ & $10.338(2)$ & $10.3399(7)$ \\
\hline \multicolumn{2}{|l|}{$V_{0}\left(\AA^{3}\right)$} & $2539.6(4)$ & $2547.7(5)$ & $2549.9(3)$ & $2548.9(6)$ & $2545.8(3)$ \\
\hline \multicolumn{2}{|l|}{$\mathrm{N}-\mathrm{P}+\mathrm{C}$} & 6420 & 6420 & 6420 & 6420 & 6397 \\
\hline \multicolumn{2}{|l|}{$R_{\mathrm{p}}$} & 15.2 & 14.5 & 12.8 & 14.0 & 13.1 \\
\hline \multicolumn{2}{|l|}{$R_{\mathrm{wp}}$} & 20.4 & 19.6 & 17.3 & 19.0 & 17.7 \\
\hline \multicolumn{2}{|l|}{$R_{\exp }$} & 11.48 & 11.42 & 11.63 & 14.09 & 14.04 \\
\hline \multicolumn{2}{|c|}{ Conventional $R_{\mathrm{p}}$} & 23.7 & 23.0 & 20.2 & 22.8 & 25.1 \\
\hline \multicolumn{2}{|c|}{ Conventional $R_{\mathrm{wp}}$} & 26.9 & 26.0 & 22.9 & 25.7 & 26.9 \\
\hline \multicolumn{2}{|c|}{ Conventional $R_{\exp }$} & 15.14 & 15.13 & 15.38 & 19.12 & 21.35 \\
\hline \multicolumn{2}{|l|}{ Chi2 } & 3.17 & 2.95 & 2.22 & 1.81 & 1.59 \\
\hline \multicolumn{2}{|c|}{ Chi2 (Bragg contr.) } & 3.65 & 3.30 & 2.49 & 2.03 & 1.67 \\
\hline \multicolumn{2}{|l|}{ DW-stat. } & 0.8168 & 0.8498 & 1.1015 & 1.2918 & 1.3967 \\
\hline \multicolumn{2}{|l|}{ DW-exp. } & 1.9642 & 1.9642 & 1.9642 & 1.9642 & 1.9715 \\
\hline \multicolumn{2}{|l|}{ GoF } & 1.8 & 1.7 & 1.5 & 1.3 & 1.2 \\
\hline \multicolumn{2}{|l|}{$R_{\mathrm{B}}$} & 10.1 & 9.84 & 7.46 & 8.07 & 6.92 \\
\hline \multicolumn{2}{|l|}{$R_{\mathrm{F}}$} & 8.17 & 8.15 & 6.38 & 7.41 & 6.94 \\
\hline
\end{tabular}

* - the numbers in parentheses are the estimated standard deviations multiplied with SCOR and refer to the last significant number; ${ }^{1}-$ Tančić et al. (2020) 


\section{APPENDIX 5}

\section{Atom parameters (in $\AA$ ) and calculated $\mathrm{Ca}$ and $\mathrm{Al}$ sof's (at.\%) for the $\boldsymbol{R}^{-} \mathbf{3 c}$ space group [without (a) and with (b) constraints]}

\begin{tabular}{|c|c|c|c|c|c|c|c|c|c|c|c|}
\hline \multicolumn{2}{|c|}{ Zone } & \multicolumn{2}{|c|}{$A(\text { core })^{1}$} & \multicolumn{2}{|c|}{$B$} & \multicolumn{2}{|c|}{$\mathrm{C}$} & \multicolumn{2}{|c|}{$\mathrm{D}$} & \multicolumn{2}{|c|}{$\mathrm{E}$ (rim) } \\
\hline & & $a$ & $\mathrm{~b}$ & $a$ & $\mathrm{~b}$ & $a$ & $\mathrm{~b}$ & $a$ & $\mathrm{~b}$ & $a$ & $\mathrm{~b}$ \\
\hline \multirow{3}{*}{ Ca1 } & $x$ & $0.625(1)$ & $0.6239(6)$ & $0.625(2)$ & $0.6248(6)$ & $0.628(1)$ & $0.6258(5)$ & $0.623(1)$ & $0.6237(4)$ & $0.620(1)$ & $0.6239(4)$ \\
\hline & $\mathrm{y}$ & 0.000 & 0.000 & 0.000 & 0.000 & 0.000 & 0.000 & 0.000 & 0.000 & 0.000 & 0.000 \\
\hline & Z & 0.250 & 0.250 & 0.250 & 0.250 & 0.250 & 0.250 & 0.250 & 0.250 & 0.250 & 0.250 \\
\hline \multirow{3}{*}{ Ca2 } & $\mathrm{x}$ & $0.129(1)$ & $0.1274(6)$ & $0.122(2)$ & $0.1228(6)$ & $0.127(1)$ & $0.1236(6)$ & $0.124(2)$ & $0.1213(5)$ & $0.127(2)$ & $0.1235(5)$ \\
\hline & $y$ & 0.000 & 0.000 & 0.000 & 0.000 & 0.000 & 0.000 & 0.000 & 0.000 & 0.000 & 0.000 \\
\hline & z & 0.250 & 0.250 & 0.250 & 0.250 & 0.250 & 0.250 & 0.250 & 0.250 & 0.250 & 0.250 \\
\hline \multirow{3}{*}{ Mn2 } & $x$ & $0.129(1)$ & n. c. & n. c. & n. c. & $0.127(1)$ & n. c. & n. c. & n. c. & $0.127(2)$ & n. c. \\
\hline & $\mathrm{y}$ & 0.000 & n. c. & n. c. & n. c. & 0.000 & n. c. & n. c. & n. c. & 0.000 & n. c. \\
\hline & z & 0.250 & n. c. & n. c. & n. c. & 0.250 & n. c. & n. c. & n. c. & 0.250 & n. c. \\
\hline \multirow{3}{*}{ Al1 } & $x$ & 0.000 & 0.000 & 0.000 & 0.000 & 0.000 & 0.000 & 0.000 & 0.000 & 0.000 & 0.000 \\
\hline & $y$ & 0.000 & 0.000 & 0.000 & 0.000 & 0.000 & 0.000 & 0.000 & 0.000 & 0.000 & 0.000 \\
\hline & $z$ & 0.000 & 0.000 & 0.000 & 0.000 & 0.000 & 0.000 & 0.000 & 0.000 & 0.000 & 0.000 \\
\hline \multirow{3}{*}{$\mathrm{Fe} 1$} & $x$ & 0.000 & 0.000 & 0.000 & 0.000 & 0.000 & 0.000 & 0.000 & 0.000 & 0.000 & 0.000 \\
\hline & $\mathrm{y}$ & 0.000 & 0.000 & 0.000 & 0.000 & 0.000 & 0.000 & 0.000 & 0.000 & 0.000 & 0.000 \\
\hline & z & 0.000 & 0.000 & 0.000 & 0.000 & 0.000 & 0.000 & 0.000 & 0.000 & 0.000 & 0.000 \\
\hline \multirow{3}{*}{$\mathrm{Al} 2$} & $x$ & 0.500 & 0.500 & 0.500 & 0.500 & 0.500 & 0.500 & 0.500 & 0.500 & 0.500 & 0.500 \\
\hline & $y$ & 0.000 & 0.000 & 0.000 & 0.000 & 0.000 & 0.000 & 0.000 & 0.000 & 0.000 & 0.000 \\
\hline & $z$ & 0.000 & 0.000 & 0.000 & 0.000 & 0.000 & 0.000 & 0.000 & 0.000 & 0.000 & 0.000 \\
\hline \multirow{3}{*}{$\mathrm{Fe} 2$} & $x$ & 0.500 & 0.500 & 0.500 & 0.500 & 0.500 & 0.500 & 0.500 & 0.500 & 0.500 & 0.500 \\
\hline & $y$ & 0.000 & 0.000 & 0.000 & 0.000 & 0.000 & 0.000 & 0.000 & 0.000 & 0.000 & 0.000 \\
\hline & $z$ & 0.000 & 0.000 & 0.000 & 0.000 & 0.000 & 0.000 & 0.000 & 0.000 & 0.000 & 0.000 \\
\hline \multirow{3}{*}{ Si } & $x$ & $0.839(1)$ & $0.8338(7)$ & $0.837(2)$ & $0.8328(7)$ & $0.834(2)$ & $0.8334(6)$ & $0.829(2)$ & $0.8316(6)$ & $0.833(2)$ & $0.8325(5)$ \\
\hline & $\mathrm{y}$ & $0.041(2)$ & $0.0395(7)$ & $0.046(2)$ & $0.0427(7)$ & $0.041(1)$ & $0.0427(6)$ & $0.045(2)$ & $0.0437(5)$ & $0.043(2)$ & $0.0418(5)$ \\
\hline & $z$ & $0.417(2)$ & $0.4174(9)$ & $0.416(3)$ & $0.418(1)$ & $0.418(2)$ & $0.4183(8)$ & $0.417(2)$ & $0.4185(8)$ & $0.416(2)$ & $0.4180(7)$ \\
\hline \multirow{3}{*}{ O1 } & $x$ & $0.204(3)$ & $0.2051(8)$ & $0.210(5)$ & $0.2096(8)$ & $0.205(2)$ & $0.2087(7)$ & $0.215(3)$ & $0.2091(6)$ & $0.211(4)$ & $0.2077(5)$ \\
\hline & $\mathrm{y}$ & $0.412(3)$ & $0.4069(7)$ & $0.405(5)$ & $0.4087(7)$ & $0.414(2)$ & $0.4088(6)$ & $0.417(3)$ & $0.4092(6)$ & $0.410(4)$ & $0.4078(5)$ \\
\hline & $z$ & $0.495(3)$ & $0.493(1)$ & $0.484(5)$ & $0.490(1)$ & $0.491(3)$ & $0.4920(9)$ & $0.490(2)$ & $0.4898(8)$ & $0.495(3)$ & $0.4923(7)$ \\
\hline \multirow{3}{*}{$\mathrm{O} 2$} & $x$ & $0.721(3)$ & $0.7278(6)$ & $0.729(4)$ & $0.7268(7)$ & $0.724(3)$ & $0.7291(6)$ & $0.721(3)$ & $0.7274(5)$ & $0.719(3)$ & $0.7276(5)$ \\
\hline & $\mathrm{y}$ & $0.967(3)$ & $0.9642(7)$ & $0.965(4)$ & $0.9633(7)$ & $0.965(2)$ & $0.9643(6)$ & $0.960(3)$ & $0.9643(5)$ & $0.958(3)$ & $0.9646(5)$ \\
\hline & $z$ & $0.382(3)$ & $0.379(1)$ & $0.391(4)$ & $0.380(1)$ & $0.386(3)$ & $0.3815(9)$ & $0.370(2)$ & $0.3773(8)$ & $0.372(4)$ & $0.3771(7)$ \\
\hline \multirow{3}{*}{$\mathrm{O} 3$} & $x$ & $0.818(4)$ & $0.8230(8)$ & $0.821(5)$ & $0.8226(8)$ & $0.818(3)$ & $0.8227(7)$ & $0.826(4)$ & $0.8236(6)$ & $0.825(5)$ & $0.8239(5)$ \\
\hline & $\mathrm{y}$ & $0.052(3)$ & $0.0624(7)$ & $0.061(5)$ & $0.0610(7)$ & $0.049(2)$ & $0.0611(7)$ & $0.067(4)$ & $0.0610(6)$ & $0.065(4)$ & $0.0612(5)$ \\
\hline & $z$ & $0.561(3)$ & $0.5678(8)$ & $0.580(5)$ & $0.5730(9)$ & $0.570(4)$ & $0.5700(7)$ & $0.565(2)$ & $0.5726(7)$ & $0.566(4)$ & $0.5716(6)$ \\
\hline \multirow{3}{*}{$\mathrm{O} 4$} & $x$ & $0.896(3)$ & $0.9087(7)$ & $0.905(4)$ & $0.9077(7)$ & $0.894(2)$ & $0.9071(6)$ & $0.907(3)$ & $0.9056(6)$ & $0.899(3)$ & $0.9064(5)$ \\
\hline & $\mathrm{y}$ & $0.893(4)$ & $0.9015(8)$ & $0.898(5)$ & $0.8998(6)$ & $0.882(2)$ & $0.8985(5)$ & $0.895(3)$ & $0.8977(5)$ & $0.895(3)$ & $0.8996(4)$ \\
\hline & $z$ & $0.892(3)$ & $0.8906(9)$ & $0.891(5)$ & $0.894(1)$ & $0.895(3)$ & $0.8945(9)$ & $0.894(2)$ & $0.8959(8)$ & $0.890(4)$ & $0.8938(7)$ \\
\hline \multicolumn{2}{|l|}{ Ca1 } & $100(4)$ & 98 & $94(6)$ & 98 & $100(4)$ & 98 & $102(2)$ & 98 & $98(4)$ & 98 \\
\hline \multicolumn{2}{|l|}{$\mathrm{Ca} 2$} & $80(20)$ & 98 & $96(4)$ & 98 & $78(12)$ & 98 & $96(2)$ & 98 & $96(14)$ & 98 \\
\hline \multicolumn{2}{|c|}{$<\mathrm{Ca}>$} & $90(12)$ & 98 & $95(5)$ & 98 & $89(8)$ & 98 & $99(2)$ & 98 & $97(9)$ & 98 \\
\hline $\mathrm{Al} 1$ & & $78(12)$ & $53(1)$ & $54(18)$ & $60(6)$ & $54(12)$ & $55(2)$ & $66(6)$ & $61(2)$ & $42(12)$ & $59(5)$ \\
\hline $\mathrm{Al} 2$ & & $84(4)$ & $74(2)$ & $68(6)$ & $62(6)$ & $70(4)$ & $64(4)$ & $60(2)$ & $54(2)$ & $62(4)$ & $56(6)$ \\
\hline$<\mathrm{Al}>$ & & $81(8)$ & $64(2)$ & $61(12)$ & $61(6)$ & $62(8)$ & $60(3)$ & $63(4)$ & $58(2)$ & $52(8)$ & $58(6)$ \\
\hline
\end{tabular}

\footnotetext{
* - the numbers in parentheses are the estimated standard deviations multiplied with SCOR and refer to the last significant number;

1 - Tančić et al. (2020); n. c. - not calculated
} 


\section{APPENDIX 6}

\section{Selected distances (in $\AA$ ) for the $R^{-} 3 c$ space group [without (a) and with (b) constraints]}

\begin{tabular}{|c|c|c|c|c|c|c|c|c|c|c|c|}
\hline \multicolumn{2}{|l|}{ Zone } & \multicolumn{2}{|c|}{ A (core) ${ }^{1}$} & \multicolumn{2}{|c|}{$B$} & & \multicolumn{2}{|c|}{$\mathrm{D}$} & \multicolumn{2}{|c|}{ E (rim) } \\
\hline & & a & $\mathrm{b}$ & $a$ & $\mathrm{~b}$ & $a$ & $\mathrm{~b}$ & $a$ & $\mathrm{~b}$ & $\bar{a}$ & N \\
\hline $\mathrm{Si}-\mathrm{O}(1)$ & $1^{\$}$ & $1.55(3)^{\circ}$ & $1.645(6)$ & 1.69(3) & $1.659(6)$ & $1.56(2)$ & $1.636(6)$ & $1.59(2)$ & $1.638(6)$ & $1.62(3)$ & $1.643(6)$ \\
\hline $\mathrm{Si}-\mathrm{O}(2)$ & 1 & $1.77(2)$ & $1.641(5)$ & $1.67(2)$ & $1.657(5)$ & 1.69(2) & $1.633(5)$ & $1.74(3)$ & $1.647(5)$ & 1.79(3) & $1.643(5)$ \\
\hline $\mathrm{Si}-\mathrm{O}(3)$ & 1 & $56(2)$ & $1.632(6)$ & $1.76(3)$ & $1.658(6)$ & 1.61(2) & $1.625(5)$ & $1.57(2)$ & $1.637(5)$ & $1.62(3)$ & $1.643(6)$ \\
\hline $\mathrm{Si}-\mathrm{O}(4)$ & 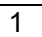 & & 3) & $1.60(4)$ & & & & & $53(8)$ & & \\
\hline$<\mathrm{Si}-\mathrm{O}\rangle$ & & $58(3)$ & $1.637(6)$ & $1.68(3)$ & $1.658(6)$ & $.55(2)$ & $1.631(6)$ & $1.64(3)$ & $1.644(6)$ & $.65(4)$ & $1.643(6)$ \\
\hline $\mathrm{O}(1)-\mathrm{O}(2)$ & 1 & $2.67(3)$ & $2.700(5)$ & $2.84(3)$ & $2.783(5)$ & $2.67(2)$ & $2.743(5)$ & $2.85(3)$ & $2.751(5)$ & $2.87(3)$ & $2.730(5)$ \\
\hline $\mathrm{O}(1)-\mathrm{O}(3)$ & 1 & $65(2)$ & $2.699(5)$ & $2.96(3)$ & $2.813(6)$ & $2.78(2)$ & $2.753(5)$ & $2.70(2)$ & $2.800(5)$ & $2.67(3)$ & $2.763(6)$ \\
\hline $\mathrm{O}(1)-\mathrm{O}(4)$ & 1 & $39(5)$ & $2.554(8)$ & $2.61(5)$ & $2.547(7)$ & $2.24(3)$ & $2.520(7)$ & $2.37(5)$ & $2.521(7)$ & $2.48(5)$ & $2.546(7)$ \\
\hline $\mathrm{O}(2)-\mathrm{O}(3)$ & 1 & $2.41(3)$ & $2.544(5)$ & $2.52(3)$ & $2.574(6)$ & $2.43(2)$ & $2.525(5)$ & $2.69(3)$ & $2.593(5)$ & $2.69(4)$ & $2.586(6)$ \\
\hline $\mathrm{O}(2)-\mathrm{O}(4)$ & 1 & $2.70(4)$ & $2.761(7)$ & $2.69(4)$ & $2.757(7)$ & $2.58(3)$ & $2.713(7)$ & 2.82(4) & $2.722(7)$ & $2.74(5)$ & $2.735(7)$ \\
\hline $\mathrm{O}(3)-\mathrm{O}(4)$ & 1 & $.56(4)$ & $2.764(7)$ & $2.82(5)$ & $2.754(7)$ & $2.48(3)$ & $2.714(7)$ & $2.67(4)$ & $2.701(7)$ & $2.69(6)$ & $2.726(7)$ \\
\hline$\langle\mathrm{O}-\mathrm{O}\rangle_{\text {tet }}$ & & $2.56(4)$ & $2.670(6)$ & $2.74(4)$ & $2.705(6)$ & $2.53(2)$ & $2.661(6)$ & $2.68(4)$ & $2.681(6)$ & $2.69(4)$ & 2.681(6) \\
\hline$Y(1)-O(4)$ & 6 & $2.10(2)$ & $1.961(3)$ & $2.01(2)$ & $1.963(3)$ & $2.18(1)$ & $1.974(3)$ & $2.01(2)$ & $1.981(3)$ & $2.08(2)$ & $1.972(3)$ \\
\hline $\mathrm{O}(4)-\mathrm{O}(4)$ & 6 & $3.08(3)$ & $2.776(6)$ & $2.88(3)$ & $2.819(6)$ & $3.27(2)$ & $2.851(6)$ & 2.91(3) & $2.881(6)$ & $3.01(4)$ & $2.838(6)$ \\
\hline $\mathrm{O}(4)-\mathrm{O}(4)$ & 6 & $2.85(3)$ & $2.770(6)$ & $2.80(4)$ & $2.734(6)$ & $2.88(3)$ & $2.731(6)$ & $2.76(3)$ & $2.720(6)$ & $2.86(4)$ & $2.740(6)$ \\
\hline$\langle\mathrm{O}-\mathrm{O}\rangle$ & & $2.96(3)$ & $2.773(6)$ & $2.84(4)$ & $2.776(6)$ & $3.08(2)$ & $2.791(6)$ & $2.84(3)$ & $2.800(6)$ & 2.94(4) & $2.789(6)$ \\
\hline$Y(2)-O(1)$ & 2 & $2.02(2)$ & $1.969(4)$ & $1.88(2)$ & $1.956(4)$ & 2.01(2) & $1.977(4)$ & & $1.962(4)$ & $2.02(2)$ & $1.972(4)$ \\
\hline$Y(2)-O(2)$ & 2 & $02(3)$ & $1.968(6)$ & $2.01(3)$ & $1.962(6)$ & 2.0 & $1.979(6)$ & 4) & 1.96 & $1.88(4)$ & $1.971(6)$ \\
\hline$Y(2)-O(3)$ & 2 & 11(2) & $1.963(3)$ & 1.91(2) & $1.956(4)$ & $2.11(2)$ & $1.971(3)$ & $1.94(2)$ & $1.964(3)$ & $1.95(3)$ & $1.967(4)$ \\
\hline$\langle Y(2)-O\rangle$ & & $2.05(2)$ & $1.967(4)$ & $1.93(2)$ & $1.958(5)$ & $2.04(2)$ & $1.976(4)$ & 1.96 & $1.965(4)$ & $1.95(3)$ & $1.970(5)$ \\
\hline$\langle Y-O\rangle$ & & $2.08(2)$ & $1.964(4)$ & $1.97(2)$ & $1.960(4)$ & $2.11(2)$ & $1.975(4)$ & $1.98(2)$ & $1.973(4)$ & $2.02(2)$ & $1.971(4)$ \\
\hline $\mathrm{O}(1)-\mathrm{O}(2)$ & 2 & $2.90(4)$ & $2.833(8)$ & $2.68(5)$ & $2.782(8)$ & $2.90(4)$ & $2.822(8)$ & $2.84(5)$ & $2.822(8)$ & $2.76(5)$ & $2.829(8)$ \\
\hline $\mathrm{O}(1)-\mathrm{O}(2)$ & 2 & $2.82(3)$ & $2.733(7)$ & $2.82(4)$ & $2.759(7)$ & $2.78(3)$ & $2.773(7)$ & $2.72(3)$ & $2.736(7)$ & $2.75(4)$ & $2.747(7)$ \\
\hline$-\mathrm{O}(3)$ & 2 & $2.86(3)$ & 2.7 & $2.74(3)$ & 2.78 & & 2.7 & 2.8 & 2.79 & 2.7 & $2.775(5)$ \\
\hline$-\mathrm{O}(3)$ & 2 & 3) & 2.84 & $2.62(3)$ & $2.749(6)$ & 3) & $2.804(5)$ & 2.7 & $2.757(5)$ & $2.85(3)$ & $2.796(6)$ \\
\hline $\mathrm{O}(2)-\mathrm{O}(3)$ & 2 & 11(4) & $2.755(7)$ & $2.74(5)$ & $2.757(7)$ & $2.97(4)$ & $2.753(7)$ & $2.72(5)$ & $2.769(7)$ & $2.74(6)$ & $2.768(7)$ \\
\hline $\mathrm{O}(2)-\mathrm{O}(3)$ & 2 & $2.84(3)$ & $2.804(7)$ & $2.80(4)$ & $2.783(7)$ & $2.86(3)$ & $2.833(7)$ & $2.69(4)$ & $2.793(7)$ & $2.67(6)$ & $2.802(7)$ \\
\hline$<\mathrm{O}-\mathrm{O}\rangle$ & & $2.90(3)$ & $2.781(6)$ & $2.73(4)$ & $2.769(7)$ & $2.89(3)$ & $2.794(6)$ & $2.76(4)$ & $2.779(6)$ & $2.76(5)$ & $2.786(7)$ \\
\hline$\langle\mathrm{O}-\mathrm{O}\rangle_{\text {oct }}$ & & $2.93(3)$ & $2.777(6)$ & $2.78(4)$ & $2.772(6)$ & $2.98(2)$ & $2.792(6)$ & $2.80(4)$ & $2.790(6)$ & $2.85(4)$ & $2.788(6)$ \\
\hline$X(1)-\mathrm{O}(1)$ & 2 & $2.59(2)$ & $2.503(5)$ & $2.46(3)$ & $2.495(5)$ & & $2.513(5)$ & & $2.492(5)$ & $2.41(3)$ & $2.484(5)$ \\
\hline$O(2)$ & 2 & & 2.5 & 2.5 & 2.4 & & & & & & $7(6)$ \\
\hline$X(1)-\mathrm{O}(2)$ & 2 & $5(2)$ & $2.328(4)$ & $2.23(2)$ & $2.312(4)$ & 2) & 2.3 & $2.37(1)$ & 2.3 & $2.34(3)$ & $2.343(4)$ \\
\hline$X(1)-\mathrm{O}(3)$ & 2 & $24(2)$ & $2.332(4)$ & $2.30(3)$ & $2.319(4)$ & $2.23(2)$ & $2.321(4)$ & 2.3 & 2.3 & $2.38(4)$ & $2.339(4)$ \\
\hline$\langle X(1)-\mathrm{O}\rangle$ & & $2.37(2)$ & $2.416(5)$ & $2.39(3)$ & $2.406(5)$ & $2.39(2)$ & 2.4 & $2.42(2)$ & $2.415(5)$ & $2.40(3)$ & $2.413(5)$ \\
\hline $\mathrm{O}(1)-\mathrm{O}(1)$ & 1 & $2.94(3)$ & $2.843(6)$ & $2.93(4)$ & $2.935(6)$ & $3.04(3)$ & $2.904(6)$ & $3.12(3)$ & $2.942(6)$ & $2.89(4)$ & $2.876(6)$ \\
\hline $\mathrm{O}(1)-\mathrm{O}(2)$ & 2 & $4.12(4)$ & $4.169(8)$ & $4.08(5)$ & $4.105(8)$ & & $4.158(8)$ & 4.01(5) & $4.119(8)$ & $3.99(5)$ & $4.129(8)$ \\
\hline$-\mathrm{O}(2)$ & 2 & & 2.8 & 2. & & & 2.8 & & & & $2.829(5)$ \\
\hline $\mathrm{O}(2)$ & 2 & $52(3)$ & 347 & 3) & 3.4 & & 3.4 & & 3.5 & (4) & $3.487(6)$ \\
\hline$-\mathrm{O}(3)$ & 2 & $0(5)$ & $2.996(8)$ & $.90(6)$ & 2.9 & 4) & 2.9 & 5) & 2.92 & $2.95(7)$ & $2.933(8)$ \\
\hline$-\mathrm{O}(2)$ & 1 & & $2.856(6)$ & 09(3) & 2.9 & & & & 2.83 & $2.80(4)$ & $2.824(6)$ \\
\hline $\mathrm{O}(2)-\mathrm{O}(2)$ & 2 & $2.67(5)$ & $2.936(9)$ & $2.89(5)$ & $2.926(9)$ & $2.77(4)$ & $2.960(9)$ & $2.92(5)$ & $2.933(9)$ & $2.89(5)$ & $2.930(9)$ \\
\hline $\mathrm{O}(2)-\mathrm{O}(3)$ & 2 & $3.33(4)$ & $3.432(8)$ & $3.51(5)$ & $3.472(8)$ & $3.45(4)$ & $3.470(8)$ & $3.43(5)$ & $3.464(8)$ & $3.44(6)$ & $3.458(8)$ \\
\hline $\mathrm{O}(2)-\mathrm{O}(3)$ & 2 & & & $2.80(3)$ & & & & & 2.7 & $2.67(4)$ & $2.802(5)$ \\
\hline $\mathrm{O}(2)-\mathrm{O}(3)$ & 2 & & 2.5 & & & & & & & & (7) \\
\hline$\langle\mathrm{O}-\mathrm{O}\rangle$ & & ) & 311 & 4) & 3.11 & & 3.1 & & 3.1 & $3.08(5)$ & $3.112(7)$ \\
\hline$X(2)-\mathrm{O}(1)$ & 2 & $29(2)$ & $2.334(4)$ & $2.34(3)$ & $2.317(5)$ & $2.27(2)$ & $2.324(5)$ & 2.1 & $2.330(5)$ & $2.28(3)$ & $2.340(5)$ \\
\hline$X(2)-\mathrm{O}(3)$ & 2 & $48(2)$ & $2.495(5)$ & $2.46(3)$ & $2.492(5)$ & $2.40(2)$ & $2.506(5)$ & $2.57(2)$ & $2.499(5)$ & $2.52(3)$ & $2.484(5)$ \\
\hline$X(2)-O(4)$ & 2 & $2.45(2)$ & $2.337(5)$ & $2.31(2)$ & $2.317(5)$ & $2.40(2)$ & $2.326(5)$ & $2.30(2)$ & $2.329(5)$ & $2.40(2)$ & $2.338(5)$ \\
\hline$X(2)-O(4)$ & 2 & $2.53(2)$ & $2.499(5)$ & $2.47(2)$ & $2.489(5)$ & $2.65(2)$ & $2.514(5)$ & $2.54(2)$ & $2.499(5)$ & $2.49(2)$ & $2.487(5)$ \\
\hline$\langle X(2)-\mathrm{O}\rangle$ & & $2.44(2)$ & & $2.40(2)$ & & & & & & $2.42(2)$ & $2.412(5)$ \\
\hline$\langle X-O\rangle$ & & $40(2)$ & & $2.40(2)$ & & & & & 2.4 & $2.41(2)$ & $2.412(5)$ \\
\hline $\mathrm{O}(1)-\mathrm{O}(1)$ & 1 & 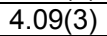 & ) & $3.86(4)$ & & & & & 3.93 & $3.92(4)$ & $3.989(6)$ \\
\hline $\mathrm{O}(1)-\mathrm{O}(3)$ & 2 & 3) & $2.846(5)$ & $2.62(3)$ & 2.72 & 3) & 28 & 27 & 2.75 & $2.85(3)$ & $2.796(6)$ \\
\hline $\mathrm{O}(1)-\mathrm{O}(3)$ & 2 & $0(3)$ & $2.996(6)$ & $.90(4)$ & $2.914(6)$ & 2.84(3) & $2.930(6)$ & 2.96(4) & $2.920(6)$ & $2.95(5)$ & $2.933(6)$ \\
\hline $\mathrm{O}(1)-\mathrm{O}(4)$ & 2 & $2.39(4)$ & $2.554(7)$ & $2.61(5)$ & $2.547(7)$ & $2.24(3)$ & $2.520(7)$ & $2.37(4)$ & $2.521(7)$ & $2.48(5)$ & $2.546(7)$ \\
\hline $\mathrm{O}(1)-\mathrm{O}(4)$ & 2 & $3.29(3)$ & $3.451(7)$ & $3.42(4)$ & $3.445(7)$ & $3.29(3)$ & $3.461(7)$ & $3.38(4)$ & $3.438(7)$ & $3.36(4)$ & $3.451(7)$ \\
\hline $\mathrm{O}(3)-\mathrm{O}(3)$ & 1 & & $4.180(5)$ & $3.94(3)$ & $4.071(6)$ & & $4.126(5)$ & & & $4.25(4)$ & $4.099(6)$ \\
\hline $\mathrm{O}(3)-\mathrm{O}(4)$ & 2 & & 2.88 & $2.88(5)$ & & 2.9 & (8) & & 2.84 & $2.78(7)$ & $2.835(8)$ \\
\hline$-\mathrm{O}(4)$ & 2 & & & & & & & & & $3.57(5)$ & $3.450(6)$ \\
\hline $\mathrm{O}(4)-\mathrm{O}(4)$ & 2 & $8(3)$ & $2.776(4)$ & $2.88(4)$ & $2.819(4)$ & 2) & 2.85 & 4) & 2.88 & $3.01(4)$ & $2.838(4)$ \\
\hline $\mathrm{O}(4)-\mathrm{O}(4)$ & 2 & $94(2)$ & $2.911(6)$ & $2.92(3)$ & $2.983(6)$ & $3.01(2)$ & $2.996(6)$ & $2.99(2)$ & $3.026(6)$ & $2.90(3)$ & $2.980(6)$ \\
\hline$\langle\mathrm{O}-\mathrm{O}\rangle$ & & $3.11(3)$ & $3.112(6)$ & $3.07(4)$ & $3.086(6)$ & $3.09(3)$ & $3.104(6)$ & $3.09(3)$ & $3.092(6)$ & $3.11(4)$ & $3.097(6)$ \\
\hline$\langle\mathrm{O}-\mathrm{O}\rangle_{\text {dod }}$ & & $3.09(4)$ & $3.114(6)$ & $3.08(4)$ & $3.096(6)$ & $3.10(3)$ & $3.110(6)$ & $3.10(4)$ & $3.104(6)$ & $3.10(4)$ & $3.104(6)$ \\
\hline$\langle D-\mathrm{O}\rangle$ & & $2.12(2)$ & $2.108(5)$ & 2.11(2) & $2.107(5)$ & 2.12(2) & $2.110(5)$ & 2.11(2) & $2.111(5)$ & $2.12(2)$ & $2.110(5)$ \\
\hline
\end{tabular}

* - the numbers in parentheses are the estimated standard deviations multiplied with SCOR and refer to the last significant number; ${ }^{\$}-$ frequency of occurrences; ${ }^{1}-$ Tančić et al. $(2020) ;\langle D-\mathrm{O}\rangle=\{\langle\mathrm{Si}-\mathrm{O}\rangle+\langle Y-\mathrm{O}\rangle+2 \times\langle X-\mathrm{O}\rangle\} / 4$ 
APPENDIX 7

Selected angles (in ${ }^{\circ}$ ) for the $\boldsymbol{R}^{-} 3 c$ space group [without (a) and with (b) constraints]

\begin{tabular}{|c|c|c|c|c|c|c|c|c|c|c|c|}
\hline \multicolumn{2}{|l|}{ Zone } & \multicolumn{2}{|c|}{$\mathrm{A}$ (core) ${ }^{1}$} & \multicolumn{2}{|c|}{ B } & \multicolumn{2}{|c|}{$\mathrm{C}$} & \multicolumn{2}{|c|}{$\mathrm{D}$} & \multicolumn{2}{|c|}{$E$ (rim) } \\
\hline & & $a$ & $\mathrm{~b}$ & $\mathrm{a}$ & $\mathrm{b}$ & $a$ & $\mathrm{~b}$ & $a$ & $\mathrm{~b}$ & $\bar{a}$ & $\mathrm{~b}$ \\
\hline $\mathrm{O}(1)-\mathrm{Si}-\mathrm{O}(2)$ & $1^{\$}$ & $107(2)$ & $110.5(4)^{1}$ & $115(2)$ & $114.2(4)$ & $111(2)$ & 114.1(4) & $117(2)$ & $113.8(4)$ & $115(2)$ & $112.4(4)$ \\
\hline $\mathrm{O}(1)-\mathrm{Si}-\mathrm{O}(3)$ & 1 & $117(2)$ & $110.9(4)$ & $118(2)$ & $116.0(5)$ & $122(2)$ & 115.2(4) & $117(2)$ & $117.5(4)$ & $112(2)$ & 114.5(5) \\
\hline $\mathrm{O}(1)-\mathrm{Si}-\mathrm{O}(4)$ & 1 & $107(3)$ & $102.5(5)$ & 104(3) & 100.4(5) & $100(2)$ & 101.0(5) & $93(3)$ & $100.0(5)$ & $102(4)$ & 101.6(5) \\
\hline $\mathrm{O}(2)-\mathrm{Si}-\mathrm{O}(3)$ & 1 & $92(2)$ & $102.0(4)$ & $95(2)$ & 101.9(4) & $95(2)$ & 101.6(4) & 108(2) & 104.3(4) & $104(3)$ & 103.9(4) \\
\hline $\mathrm{O}(2)-\mathrm{Si}-\mathrm{O}(4)$ & 1 & 114(3) & $115.2(5)$ & 111(3) & 112.6(5) & $116(3)$ & 112.5(5) & 111(3) & 111.1(5) & 109(3) & 112.7(3) \\
\hline $\mathrm{O}(3)-\mathrm{Si}-\mathrm{O}(4)$ & 1 & $118(3)$ & $115.9(5)$ & 114(3) & $112.3(5)$ & 114(3) & $113.0(5)$ & $110(3)$ & $110.3(5)$ & $115(4)$ & 112.2(5) \\
\hline \multicolumn{2}{|l|}{$<\mathrm{O}-\mathrm{Si}-\mathrm{O}>$} & $109(2)$ & 109.5(4) & $110(2)$ & $109.6(5)$ & $110(2)$ & $109.6(4)$ & $109(2)$ & $109.5(4)$ & $110(3)$ & 109.6(4) \\
\hline $\mathrm{O}(4)-Y(1)-\mathrm{O}(4)$ & 6 & $94(2)$ & 90.1(3) & $92(2)$ & $91.8(3)$ & $97(1)$ & $92.4(3)$ & $93(2)$ & 93.3(3) & $93(2)$ & $92.0(3)$ \\
\hline$O(4)-Y(1)-O(4)$ & 6 & $86(2)$ & $89.9(3)$ & $88(2)$ & $88.2(3)$ & $83(1)$ & $87.6(3)$ & $87(2)$ & $86.7(3)$ & $87(2)$ & $88.0(3)$ \\
\hline \multicolumn{2}{|l|}{$<\mathrm{O}-Y(1)-\mathrm{O}>$} & $90(2)$ & $90.0(3)$ & $90(2)$ & $90.0(3)$ & $90(1)$ & $90.0(3)$ & $90(2)$ & $90.0(3)$ & $90(2)$ & $90.0(3)$ \\
\hline $\mathrm{O}(1)-Y(2)-\mathrm{O}(2)$ & 2 & $92(2)$ & $92.0(4)$ & $87(2)$ & $90.5(4)$ & $92(2)$ & $91.0(4)$ & $92(2)$ & $91.4(2)$ & $90(3)$ & $91.7(4)$ \\
\hline $\mathrm{O}(1)-Y(2)-\mathrm{O}(2)$ & 2 & $88(2)$ & $88.0(3)$ & $93(2)$ & $89.5(3)$ & $88(2)$ & $89.0(3)$ & $88(2)$ & $88.6(2)$ & $90(2)$ & $88.3(3)$ \\
\hline $\mathrm{O}(1)-Y(2)-\mathrm{O}(3)$ & 2 & $88(1)$ & $87.3(3)$ & $92(2)$ & $90.7(3)$ & $91(1)$ & $89.5(3)$ & $91(2)$ & $88.2(1)$ & $88(2)$ & $89.6(3)$ \\
\hline $\mathrm{O}(1)-Y(2)-\mathrm{O}(3)$ & 2 & $92(1)$ & $92.7(3)$ & $88(2)$ & $89.3(3)$ & $89(1)$ & $90.5(3)$ & $89(1)$ & (1) & $92(2)$ & $0.4(3)$ \\
\hline $\mathrm{O}(2)-Y(2)-\mathrm{O}(3)$ & 2 & $93(2)$ & $89.0(4)$ & $89(2)$ & $89.5(4)$ & $92(2)$ & $88.4(4)$ & $91(2)$ & (4) & 91(3) & $9.3(4)$ \\
\hline $\mathrm{O}(2)-Y(2)-\mathrm{O}(3)$ & 2 & $87(2)$ & 91.0(3) & $91(2)$ & $90.5(4)$ & $88(2)$ & (3) & $89(2)$ & (3) & $89(3)$ & $90.7(4)$ \\
\hline \multicolumn{2}{|l|}{$<O-Y(2)-O>$} & $90(2)$ & $90.0(3)$ & $90(2)$ & $90.0(4)$ & $90(2)$ & $90.0(3)$ & $90(2)$ & $90.0(2)$ & $90(2)$ & $90.0(4)$ \\
\hline \multicolumn{2}{|l|}{$<O-Y-O>$} & $90(2)$ & $90.0(3)$ & $90(2)$ & $90.0(4)$ & $90(2)$ & $90.0(3)$ & $90(2)$ & $90.0(2)$ & $90(2)$ & $90.0(4)$ \\
\hline $\mathrm{O}(1)-X(1)-\mathrm{O}(1)$ & 1 & $69(1)$ & $69.2(2)$ & $73(2)$ & $72.0(3)$ & $69(1)$ & $70.6(2)$ & $77(1)$ & $72.4(3)$ & $74(2)$ & $70.8(3)$ \\
\hline $\mathrm{O}(1)-X(1)-\mathrm{O}(2)$ & 2 & $111(2)$ & $112.8(3)$ & $109(2)$ & $110.7(3)$ & $110(2)$ & $111.8(3)$ & $109(2)$ & $111.5(3)$ & $110(2)$ & $112.3(3)$ \\
\hline $\mathrm{O}(1)-X(1)-\mathrm{O}(2)$ & 2 & 1) & $71.7(2)$ & $70(1)$ & 70.6 & 71.7(9) & (2) & $71(1)$ & (2) & 71(1) & $71.7(2)$ \\
\hline $\mathrm{O}(1)-X(1)-\mathrm{O}(2)$ & 2 & 3(1) & $91.9(3)$ & $93(2)$ & $92.2(3)$ & $90(1)$ & $90.6(3)$ & $93(1)$ & $92.9(3)$ & 94(2) & $92.5(3)$ \\
\hline $\mathrm{O}(1)-X(1)-\mathrm{O}(3)$ & 2 & (1) & $76.5(3)$ & $75(2)$ & 74.4(3) & $70(1)$ & $74.5(3)$ & $74(2)$ & $74.4(3)$ & $76(2)$ & $74.9(3)$ \\
\hline $\mathrm{O}(2)-X(1)-\mathrm{O}(2)$ & 1 & $74(1)$ & $69.7(2)$ & $74(1)$ & $71.2(2)$ & $76(1)$ & $70.9(2)$ & $70(1)$ & $69.2(2)$ & $70(2)$ & $69.2(2)$ \\
\hline $\mathrm{O}(2)-X(1)-\mathrm{O}(2)$ & 2 & $70(2)$ & $74.8(3)$ & $74(2)$ & $74.9(3)$ & $72(2)$ & $75.5(3)$ & $75(2)$ & $74.7(3)$ & $74(2)$ & $74.6(3)$ \\
\hline $\mathrm{O}(2)-X(1)-\mathrm{O}(3)$ & 2 & $92(2)$ & $90.4(3)$ & $92(2)$ & $92.2(3)$ & $96(2)$ & $91.7(3)$ & $91(2)$ & $91.7(3)$ & $91(3)$ & $91.5(3)$ \\
\hline $\mathrm{O}(2)-X(1)-\mathrm{O}(3)$ & 2 & $75(1)$ & $70.8(2)$ & $70(1)$ & 70.5 & $76(1)$ & $7(2)$ & $68(1)$ & & $67(2)$ & $70.9(2)$ \\
\hline $\mathrm{O}(2)-X(1)-\mathrm{O}(3)$ & 2 & 1) & $66.2(2)$ & 1 & 67.5 & $65.8(9)$ & 2) & 1) & (2) & $69(2)$ & $67.1(2)$ \\
\hline \multicolumn{2}{|l|}{$<0-X(1)-0>$} & $80(1)$ & $80.5(3)$ & $80(2)$ & $80.5(3)$ & $81(1)$ & $80.4(3)$ & $80(1)$ & $80.6(3)$ & $80(2)$ & $80.6(3)$ \\
\hline $\mathrm{O}(1)-X(2)-\mathrm{O}(1)$ & 1 & $127(2)$ & $121.0(3)$ & 112(2) & $115.5(3)$ & $126(1)$ & $117.0(3)$ & 119(2) & $115.1(3)$ & $119(2)$ & $117.0(3)$ \\
\hline $\mathrm{O}(1)-X(2)-\mathrm{O}(3)$ & 2 & $78(1)$ & $72.1(2)$ & $66(1)$ & $69.6(2)$ & $76(1)$ & $70.9(2)$ & $71(1)$ & $69.5(2)$ & $73(1)$ & $70.8(2)$ \\
\hline $\mathrm{O}(1)-X(2)-\mathrm{O}(3)$ & 2 & $75(1)$ & $76.6(2)$ & $74(2)$ & $74.5(3)$ & $75(1)$ & $74.6(2)$ & $76(2)$ & $74.3(2)$ & $76(2)$ & $74.8(3)$ \\
\hline $\mathrm{O}(1)-X(2)-\mathrm{O}(4)$ & 2 & $61(1)$ & $66.3(3)$ & $68(2)$ & $66.7(3)$ & $57(1)$ & $65.6(3)$ & $64(2)$ & $65.5(3)$ & $64(2)$ & $66.0(3)$ \\
\hline $\mathrm{O}(1)-X(2)-\mathrm{O}(4)$ & 2 & $86(1)$ & & 91 & & $84(1)$ & & $90(2)$ & & $90(2)$ & $91.2(3)$ \\
\hline $\mathrm{O}(3)-X(2)-\mathrm{O}(3)$ & 1 & $113(1)$ & $113.8(2)$ & 107(2) & 109.6 & $112(1)$ & $8(2)$ & 114(1) & $109.4(2)$ & $115(2)$ & 111.2(3) \\
\hline$-X(2)-O(4)$ & 2 & $69(2)$ & $70.5(3)$ & $71(2)$ & $70.5(3)$ & $70(1)$ & 70.1(3) & $69(2)$ & $69.4(3)$ & $67(2)$ & $69.5(3)$ \\
\hline $\mathrm{O}(3)-X(2)-\mathrm{O}(4)$ & 2 & $90(1)$ & 91.9(2) & $94(2)$ & $91.4(2)$ & $88(1)$ & $90.8(2)$ & $90(1)$ & $90.8(2)$ & $93(2)$ & $91.3(2)$ \\
\hline $\mathrm{O}(4)-X(2)-\mathrm{O}(4)$ & 2 & $76(1)$ & $70.0(2)$ & $74(2)$ & $71.7(2)$ & $80.7(9)$ & $72.0(2)$ & $73(1)$ & $73.2(2)$ & $76(2)$ & $72.0(2)$ \\
\hline $\mathrm{O}(4)-X(2)-\mathrm{O}(4)$ & 2 & $72(1)$ & $73.9(2)$ & $75(1)$ & $76.6(2)$ & 73.1(9) & $76.4(2)$ & $76(1)$ & $77.5(2)$ & $73(1)$ & $76.2(2)$ \\
\hline \multicolumn{2}{|l|}{$<\mathrm{O}-X(2)-\mathrm{O}>$} & $81(1)$ & $81.1(2)$ & $80(2)$ & $80.6(3)$ & $80(1)$ & $80.6(2)$ & $81(2)$ & $80.4(2)$ & $81(2)$ & $80.7(3)$ \\
\hline \multicolumn{2}{|l|}{$<0-X-O>$} & $80(1)$ & $80.8(2)$ & $80(2)$ & $80.6(3)$ & $80(1)$ & $80.5(2)$ & $80(2)$ & $80.5(2)$ & $80(2)$ & $80.6(3)$ \\
\hline
\end{tabular}

* - the numbers in parentheses are the estimated standard deviations multiplied with SCOR and refer to the last significant number; ${ }^{\$}$ - frequency of occurrences; ${ }^{1}$ - Tančić et al. (2020) 


\section{APPENDIX 8}

Number $\left(\mathrm{N}^{\circ}\right)$ of calculated Bragg's positions $\left(\mathrm{Y}_{\text {calc }}\right)$ and differences between starting and ending corresponding $Y_{\text {calc's }}\left(\Delta Y_{\text {calc, }}\right.$, in $\left.{ }^{\circ}\right)$

\begin{tabular}{|c|c|c|c|c|c|c|c|c|c|c|c|c|c|c|}
\hline$h k l$ & \multicolumn{2}{|c|}{$1040(-)$} & \multicolumn{2}{|c|}{$1042(-)$} & \multicolumn{2}{|c|}{$880(+)$} & \multicolumn{2}{|c|}{$884(+)$} & \multicolumn{2}{|c|}{$1220(-)$} & \multicolumn{2}{|c|}{$1222(+)$} & \multicolumn{2}{|c|}{$888(+)$} \\
\hline Zone & $\mathrm{N}^{0}$ & $\Delta \mathrm{Y}_{\text {calc }}$ & $\mathrm{N}^{0}$ & $\Delta \mathrm{Y}_{\text {calc }}$ & $\mathrm{N}^{0}$ & $\Delta \mathrm{Y}_{\text {calc }}$ & $\mathrm{N}^{0}$ & $\Delta \mathrm{Y}_{\text {calc }}$ & $\mathrm{N}^{0}$ & $\Delta \mathrm{Y}_{\text {calc }}$ & $\mathrm{N}^{0}$ & $\Delta \mathrm{Y}_{\text {calc }}$ & $\mathrm{N}^{0}$ & $\Delta \mathrm{Y}_{\text {calc }}$ \\
\hline$A^{1}$ & \multirow{5}{*}{6} & 0.057 & \multirow{5}{*}{4} & 0.043 & \multirow{5}{*}{2} & 0.046 & \multirow{5}{*}{4} & 0.071 & \multirow{5}{*}{2} & 0.018 & \multirow{5}{*}{7} & 0.074 & \multirow{5}{*}{2} & 0.116 \\
\hline B & & 0.118 & & 0.088 & & 0.094 & & 0.143 & & 0.036 & & 0.152 & & 0.234 \\
\hline $\mathrm{C}$ & & 0.080 & & 0.060 & & 0.065 & & 0.098 & & 0.024 & & 0.104 & & 0.161 \\
\hline $\mathrm{D}$ & & 0.058 & & 0.043 & & 0.046 & & 0.071 & & 0.018 & & 0.075 & & 0.116 \\
\hline$E$ & & 0.145 & & 0.109 & & 0.116 & & 0.177 & & 0.044 & & 0.187 & & 0.289 \\
\hline
\end{tabular}

1 - Tančić et al. (2020); all reflections are marked with $h k / s$ belonging to the la $\overline{3} d$ space group; the symbols "+" and "-" denote the presence and the abscence of doublets, respectively 


\section{APPENDIX 9}

Differences between Al sof's (in at. \%), and average $<Y-O>$ and $<0-0>$ distances (in $A$ ) in octahedral sites and calculated degree of ordering $(m)$ and intersite distribution coefficient $\left(K_{1-2}\right)$ for the $R 3 c$ and $F d d d$ space groups [without (a) and with (b) constraints]

\begin{tabular}{|c|c|c|c|c|c|c|c|c|c|c|c|}
\hline \multicolumn{2}{|c|}{ Zone } & \multicolumn{2}{|c|}{$\mathrm{A}(\text { core })^{1}$} & \multicolumn{2}{|c|}{$B$} & \multicolumn{2}{|c|}{$C$} & \multicolumn{2}{|c|}{$\mathrm{D}$} & \multicolumn{2}{|c|}{ E (rim) } \\
\hline & & $a$ & $b$ & $a$ & b & $a$ & $b$ & $a$ & $b$ & $a$ & $b$ \\
\hline \multirow[b]{2}{*}{$\Delta \mathrm{Al}$} & $R 3 c$ & $6(8)$ & $21(2)$ & $14(12)$ & $2(6)$ & $16(8)$ & $9(3)$ & $6(4)$ & $7(2)$ & $20(8)$ & $3(6)$ \\
\hline & Fddd & $4(8)$ & $4(10)$ & $0(10)$ & $4(12)$ & $2(8)$ & $6(8)$ & $4(5)$ & $4(4)$ & $4(8)$ & $8(1)$ \\
\hline \multirow{2}{*}{$\Delta<Y-O>$} & $R 3 c$ & $0.05(2)$ & $0.006(4)$ & $0.08(2)$ & $0.005(4)$ & $0.14(2)$ & $0.002(4)$ & $0.05(2)$ & $0.016(4)$ & $0.13(2)$ & $0.002(4)$ \\
\hline & Fddd & $0.02(3)$ & $0.000(4)$ & $0.02(3)$ & $0.001(4)$ & $0.04(3)$ & $0.000(4)$ & $0.02(3)$ & $0.005(4)$ & $0.03(4)$ & $0.001(4)$ \\
\hline \multirow{2}{*}{$\Delta<\mathrm{O}-\mathrm{O}>$} & $R 3 c$ & $0.06(3)$ & $0.008(6)$ & $0.11(4)$ & $0.007(6)$ & $0.19(2)$ & $0.003(3)$ & $0.08(4)$ & $0.021(6)$ & $0.18(4)$ & $0.003(6)$ \\
\hline & Fddd & $0.04(4)$ & $0.001(6)$ & $0.02(4)$ & $0.001(6)$ & $0.06(4)$ & $0.001(6)$ & $0.02(4)$ & $0.007(6)$ & $0.05(6)$ & $0.000(6)$ \\
\hline \multirow[b]{2}{*}{$m$} & $R 3 c$ & 0.037 & 0.165 & 0.115 & 0.016 & 0.129 & 0.076 & 0.048 & 0.043 & 0.192 & 0.026 \\
\hline & Fddd & 0.024 & 0.031 & 0 & 0.032 & 0.015 & 0.051 & 0.031 & 0.034 & 0.032 & 0.069 \\
\hline \multirow[b]{2}{*}{$K_{1-2}$} & $R 3 c$ & 1.481 & 2.524 & 1.810 & 1.088 & 1.988 & 1.454 & 1.294 & 1.333 & 2.253 & 1.131 \\
\hline & Fddd & 1.312 & 1.190 & 1 & 1.185 & 1.095 & 1.282 & 1.190 & 1.179 & 1.185 & 1.391 \\
\hline
\end{tabular}

* - the numbers in parentheses are the estimated standard deviations multiplied with SCOR and refer to the last significant number; ${ }^{1}$ - Tančić et al. (2020) 
APPENDIX 10

Variations of the $\mathrm{Fe}^{3+}$ and $\mathrm{Al}^{3+}$ over the octahedral sites in the $R^{-3} 3 c$ space group by $\Delta \mathrm{Al}$

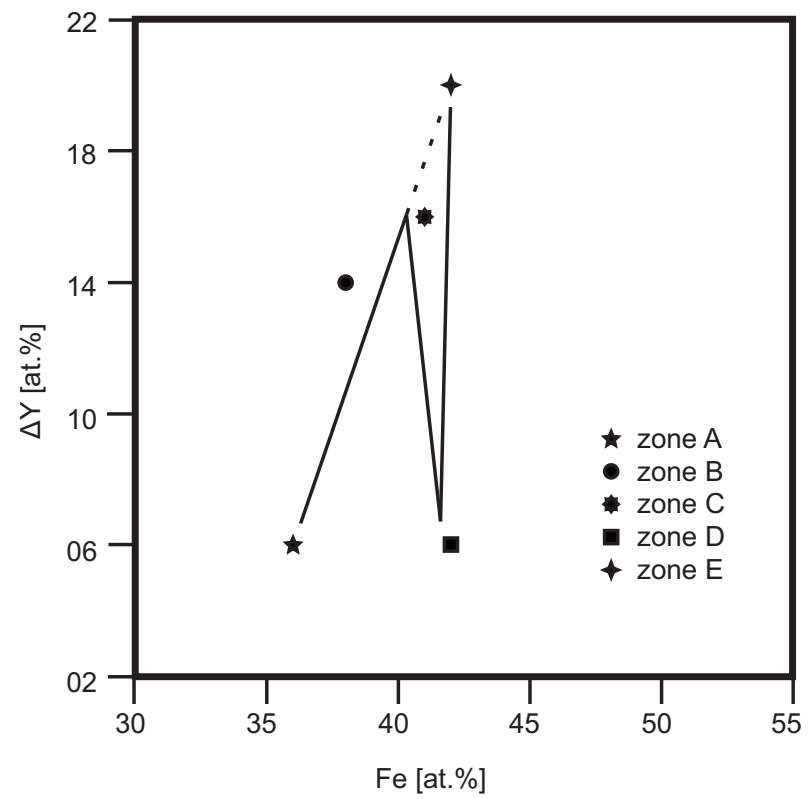




\section{APPENDIX 11}

Determined Si-Y1, Si-X2 and $Y 1-X 2$ distances (in $A)$

\begin{tabular}{|c|c|c|c|c|c|}
\hline & A (core) & B & C & D & E (rim) \\
\hline $\mathrm{Si}-Y 1$ & $3.24(1)$ & $3.32(1)$ & $3.31(2)$ & $3.44(2)$ & $3.35(2)$ \\
\hline $\mathrm{Si}-X 2$ & $3.38(1)$ & $3.43(2)$ & $3.42(1)$ & $3.49(2)$ & $3.44(2)$ \\
\hline$Y 1-X 2$ & $3.377(6)$ & $3.308(7)$ & $3.361(4)$ & $3.327(8)$ & $3.358(5)$ \\
\hline
\end{tabular}




\section{APPENDIX 12}

Variations of the $\mathrm{Fe}^{3+}$ and $\mathrm{Al}^{3+}$ over the octahedral sites in the $R^{-} 3 c$ space group, by average: $A-\langle Y-O\rangle$; B $-<0-O>$ distances with constraints
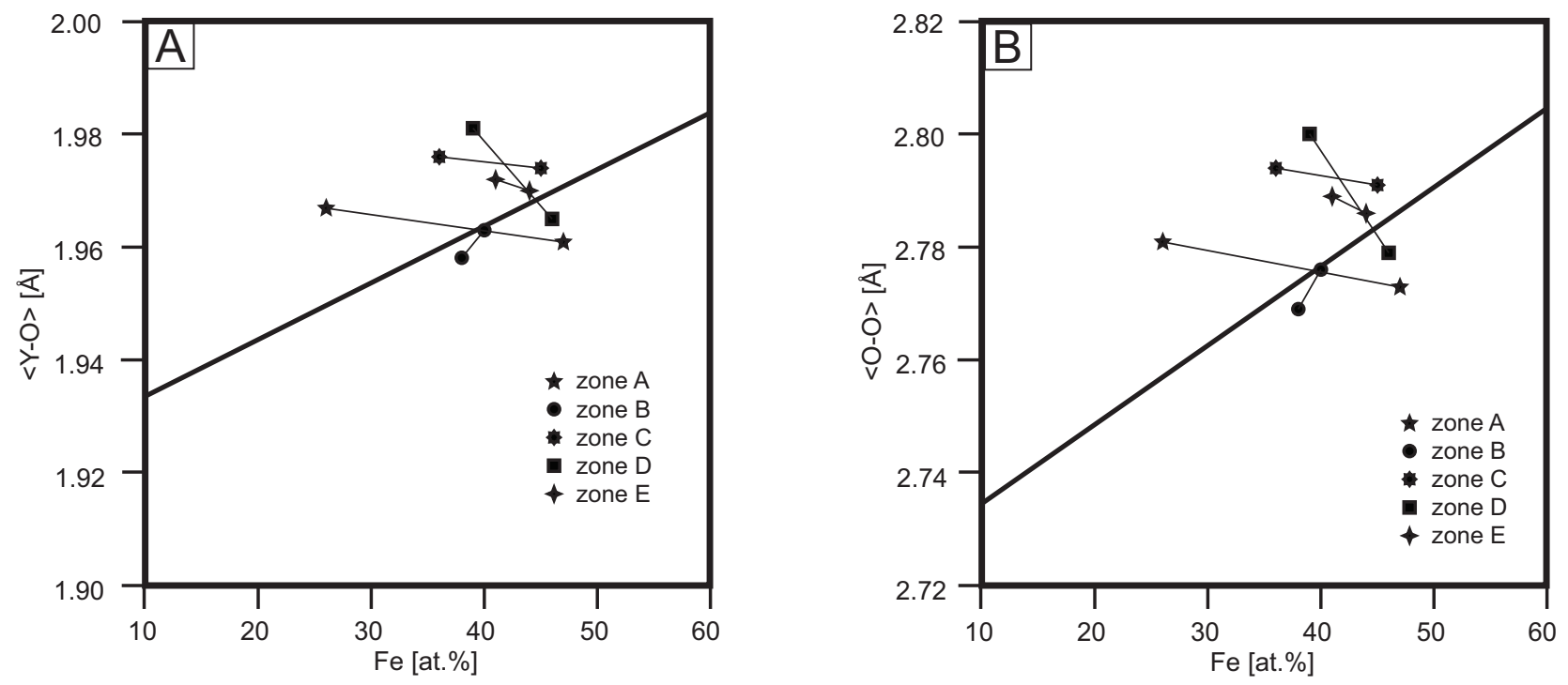

Linear Grs-Adr joins (Novak and Gibbs, 1971) were also plotted for comparison 


\section{APPENDIX 13}

Calculated polyhedral volumes, quadratic elongations and angle variances in the tetrahedron and two octahedrons for the $R^{-} 3 c$ space group [without (a) and with (b) constraints]

\begin{tabular}{|c|c|c|c|c|c|c|c|c|c|c|c|}
\hline & \multirow[t]{2}{*}{ Zone } & \multicolumn{2}{|c|}{ A (core) ${ }^{1}$} & \multicolumn{2}{|c|}{$B$} & \multicolumn{2}{|c|}{$\mathrm{C}$} & \multicolumn{2}{|c|}{$\mathrm{D}$} & \multicolumn{2}{|c|}{$E$ (rim) } \\
\hline & & $a$ & $b$ & $\mathrm{a}$ & $b$ & a & $\mathrm{b}$ & a & $\mathrm{b}$ & a & $b$ \\
\hline \multirow{3}{*}{ Tetrahedron } & $\begin{array}{l}\text { polyhedral } \\
\text { volume }\end{array}$ & 1.94156 & 2.22042 & 2.36897 & 2.30182 & 1.83061 & 2.19356 & 2.22672 & 2.24588 & 2.26404 & 2.24952 \\
\hline & $\begin{array}{l}\text { quadratic } \\
\text { elongation }\end{array}$ & 1.02945 & 1.00892 & 1.02100 & 1.01101 & 1.03708 & 1.01028 & 1.02401 & 1.00103 & 1.01163 & 1.00722 \\
\hline & $\begin{array}{c}\text { angle } \\
\text { variance }\end{array}$ & 92.57748 & 36.87321 & 75.59731 & 44.99269 & 106.96640 & 42.07073 & 79.89321 & 40.74125 & 28.39711 & 29.40202 \\
\hline \multirow{3}{*}{ Octahedron-1 } & $\begin{array}{c}\text { polyhedral } \\
\text { volume }\end{array}$ & 12.19868 & 10.04237 & 10.78950 & 10.07710 & 13.44318 & 10.22631 & 10.72094 & 10.31607 & 11.88520 & 10.21280 \\
\hline & $\begin{array}{l}\text { quadratic } \\
\text { elongation }\end{array}$ & 1.00632 & 1.00000 & 1.00073 & 1.00096 & 1.01843 & 1.00189 & 1.00268 & 1.00344 & 1.00259 & 1.00126 \\
\hline & $\begin{array}{c}\text { angle } \\
\text { variance }\end{array}$ & 21.30664 & 0.01247 & 2.55438 & 3.37979 & 58.95992 & 6.54798 & 9.23038 & 11.80922 & 8.93208 & 4.41588 \\
\hline \multirow{3}{*}{ Octahedron-2 } & $\begin{array}{c}\text { polyhedral } \\
\text { volume }\end{array}$ & 11.48921 & 10.12718 & 9.59907 & 10.00429 & 11.34777 & 10.27427 & 9.92271 & 10.11234 & 9.82322 & 10.19424 \\
\hline & $\begin{array}{l}\text { quadratic } \\
\text { elongation }\end{array}$ & 1.00292 & 1.00131 & 1.00341 & 1.00011 & 1.00232 & 1.00041 & 1.00263 & 1.00041 & 1.00226 & 1.00037 \\
\hline & $\begin{array}{c}\text { angle } \\
\text { variance }\end{array}$ & 7.32937 & 4.60396 & 6.14373 & 0.36546 & 3.94984 & 1.45068 & 2.53165 & 1.48096 & 1.90723 & 1.32142 \\
\hline
\end{tabular}

${ }^{1}$ - Tančić et al. (2020) 


\section{APPENDIX 14}

Different presentation models of the $\mathrm{Fe}^{3+}$ and $\mathrm{Al}^{3+}$ variations over the octahedral sites by average $\langle Y-O\rangle$ distances: $A-($ pseudo) cyclical of the oscillatory nature; B - (pseudo) rotational or spiral
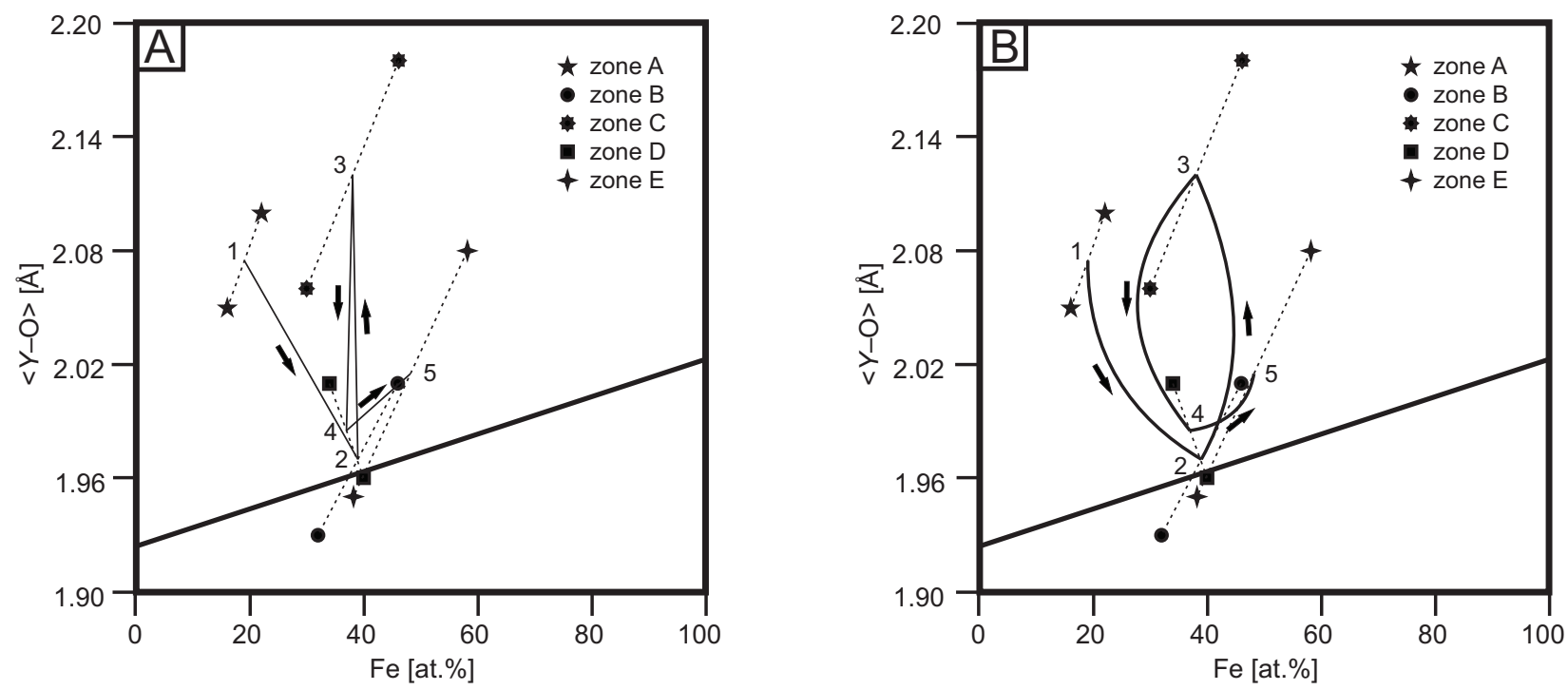

Linear Grs-Adr joins (Novak and Gibbs, 1971) were also plotted for comparison 